\title{
Modelling multi-phase halogen chemistry in the remote marine boundary layer: investigation of the influence of aerosol size resolution on predicted gas- and condensed-phase chemistry
}

\author{
D. Lowe, D. Topping, and G. McFiggans \\ School of Earth, Atmospheric and Environmental Science, University of Manchester, Manchester, UK
}

Received: 4 February 2009 - Published in Atmos. Chem. Phys. Discuss.: 2 March 2009

Revised: 26 June 2009 - Accepted: 30 June 2009 - Published: 15 July 2009

\begin{abstract}
A coupled box model of photochemistry and aerosol microphysics which explicitly accounts for sizedependent chemical properties of the condensed-phase has been developed to simulate the multi-phase chemistry of chlorine, bromine and iodine in the marine boundary layer (MBL). The model contains separate seasalt and nonseasalt modes, each of which may be composed of 1-16 size-bins. By comparison of gaseous and aerosol compositions predicted using different size-resolutions with both fixed and size-dependent aerosol turnover rates, it was found that, for halogen-activation processes, the physical property initialisation of the aerosol-mode has a significant influence on gas-phase chemistry. Failure to adequately represent the appropriate physical properties can lead to substantial errors in gas-phase chemistry. The size-resolution of condensedphase composition has a less significant influence on gasphase chemistry.
\end{abstract}

\section{Introduction}

Recent measurements have shown that halogens can play a major role in the destruction of tropospheric ozone - causing up to $50 \%$ of the ozone loss in the remote marine boundary layer (MBL) (Read et al., 2008). It has been shown that seasalt particles generated from the sea surface via wind shear are the major source of inorganic halogen species in the MBL (cf. Keene et al., 1999; Sander et al., 2003) and size-segregated measurements of aerosols in the MBL have shown that most seasalt aerosol particles have a $\mathrm{pH}$ of 3.54.5, varying across the particle size-range (Keene et al., 2002, 2004). It may be expected then, that to investigate the causes and impacts of such variations in composition, a sizeresolved aerosol model must be used.

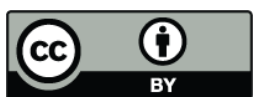

Correspondence to: D. Lowe (douglas.lowe@manchester.ac.uk)
Detailed MBL mixed-phase chemistry has historically been studied using photochemical box models which treat the condensed-phase as a simple reactive volume, using representative aerosol microphysical properties to determine gas-aerosol exchange rates but not allowing them to evolve through time (e.g. Model Of Chemistry Considering Aerosols, MOCCA, Sander and Crutzen, 1996). Recent work to improve the treatment of the condensed-phase have focussed on one of two aspects: either size-resolved chemistry or size-resolved aerosol microphysics.

The first approach simply consists of increasing the number of condensed-phases, giving each separate microphysical properties which relate to a size-resolved aerosol distribution, but still without considering how these properties change with time (although replenishment of condensedphase chemical constituents by aerosol turn-over is generally incorporated). This method has been used in the study of Pszenny et al. (2004), who adapted MOCCA to use 14 separate condensed-phases, 7 seasalt and 7 non-seasalt; and that of Toyota et al. (2001) using SEAMAC (size-SEgregated Aerosol model for Marine Air Chemistry), which consists of 8 separate condensed-phases, all seasalt, and uses the ASAD chemical solver (Carver et al., 1997).

The second approach involves overlaying the mixed-phase chemistry scheme onto a full aerosol microphysical scheme, which is used to determine the aerosol properties needed by the chemistry scheme. This approach has been followed by von Glasow et al. (2002), who created their 1-D column model MISTRA-MPIC (MIcrophysical STRAtus model - Max-Planck-Institut für Chemie version) by combining a detailed chemistry scheme with the aerosol microphysical model of Bott et al. (1996). Condensed-phase chemistry is calculated using two sections, one seasalt and one "sulphate"; the microphysical properties of each being determined by combining the properties of all aerosol sections larger than $0.5 \mu \mathrm{m}$ for the seasalt mode, and all sections smaller than $0.5 \mu \mathrm{m}$ for the "sulphate" mode. 

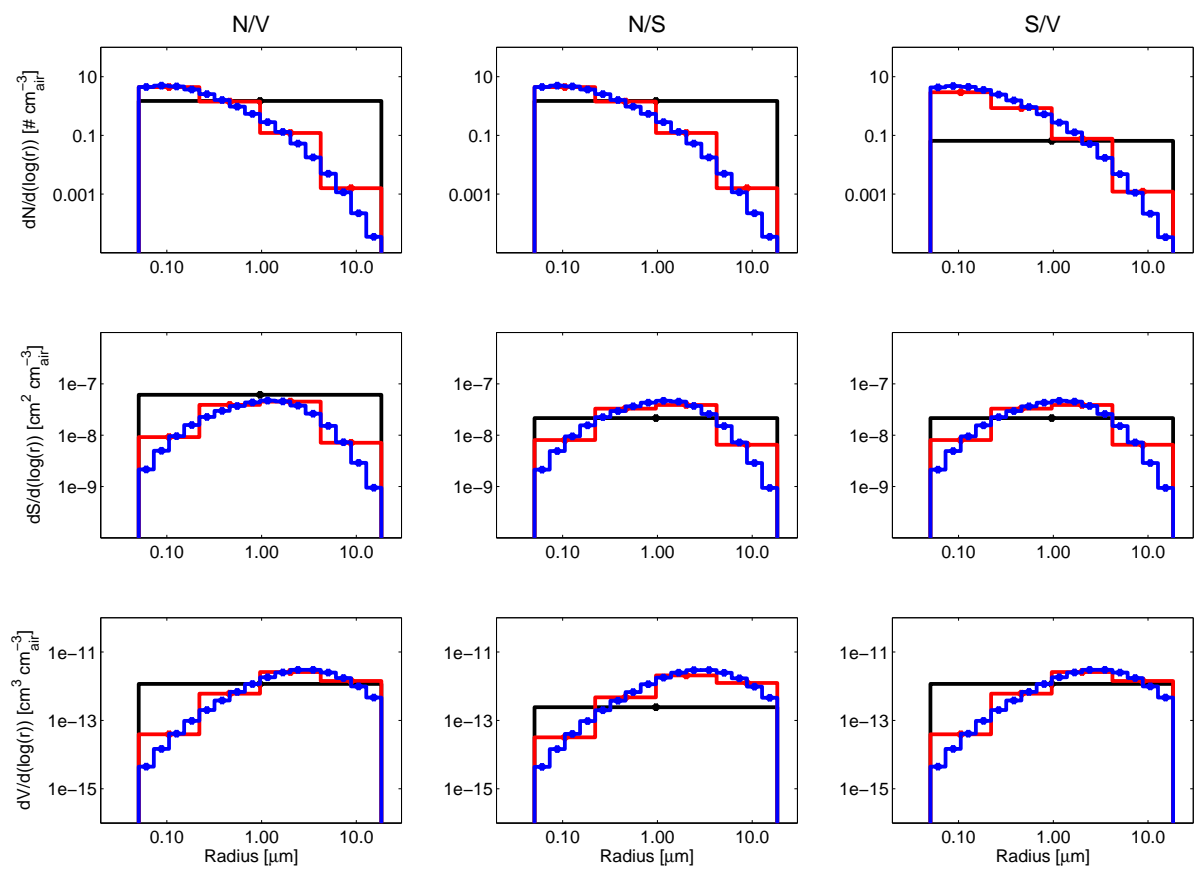

Fig. 1. Comparison of the moments (number, surface area and volume) of the seasalt mode, using the Porter and Clarke (1997) based distribution, when using the three different initialisation methods (NV, NS and SV). Blue, red and black lines represent the 16-, 4-, and 1-bin distributions, respectively.

The aim of this paper is to investigate the relative importance of size-resolution of both condensed-phase chemistry and aerosol microphysics to the chemistry in the remote MBL. A previous modelling study (Toyota et al., 2001) has shown that gas-phase chemistry is dependent on the sizeresolution of the aerosol mode but it is unclear from that work if the dependence is due to microphysical or chemical influences. An intention of the current work is to clarify the causes of this dependence.

\section{Methods}

In order to address these questions a highly detailed aerosol model (MANIC: Microphysical Aerosol Numerical model Incorporating Chemistry) has been developed, which can treat both condensed-phase chemistry and aerosol microphysics at a high-resolution. MANIC is a zero-dimensional aerosol model designed for studying multi-phase chemistry. The Kinetic PreProcessor (KPP) program (Damian et al., 2002) is used to construct a system of ODEs representing the chemical continuity equations which are solved using the 3rd order Rosenbrock solver (RODAS3, Sandu et al., 1997) packaged with KPP. All gas- and condensed-phase chemical reactions are solved in the same time-step; avoiding any errors associated with operator-splitting (cf. Sportisse, 2000). For this same reason the physical processes affecting the condensed-phase are solved within the same time-step as the chemistry. The condensed-phase can be duplicated to form several separate sections; which, during the chemistry step, only interact via the gas-phase. These sections can be organised into a number of completely separate modes; or into one, or more, series of particle-size defined sections between which condensed-mass can be moved due to particle growth or physical processes. The microphysical properties of each condensed-phase are re-calculated for every internal timestep taken by the Rosenbrock solver. For this study we will represent the condensed-phase using two externally mixed aerosol modes, each of which could have a variety of different size resolutions: either $1,2,4,8$, or 16 size-bins.

The size-bins of each mode are defined using the "dry" particle radius (calculated from the total particle mass excluding the $\mathrm{H}_{2} \mathrm{O}$ ). The dry-radius is used in order that particle composition can be tracked independently of changes in RH. Growth of aerosol particles is dealt with using the Moving Centre method (Jacobson, 1997). The edges of the size-bins are fixed, and evenly distributed in logarithmic dryradius space (the size range of each mode is independent of the other, and the two may overlap). Processes such as particle emission and deposition can be treated as if the sizestructure is fully-stationary; no new size-bins need be created to accommodate the new particles. The particles in each size-bin are assumed to have the same radius, which is used to define the "centre" point of the size-bin. This centre point moves within the size-bin as the particles grow during the chemistry phase. At set time intervals the size-distribution is recalculated, where the centre point of a size-bin has passed 

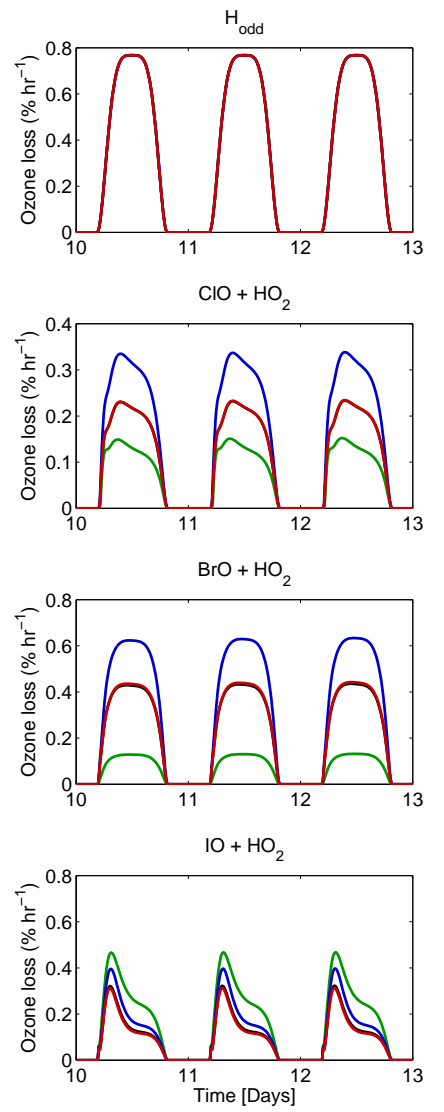
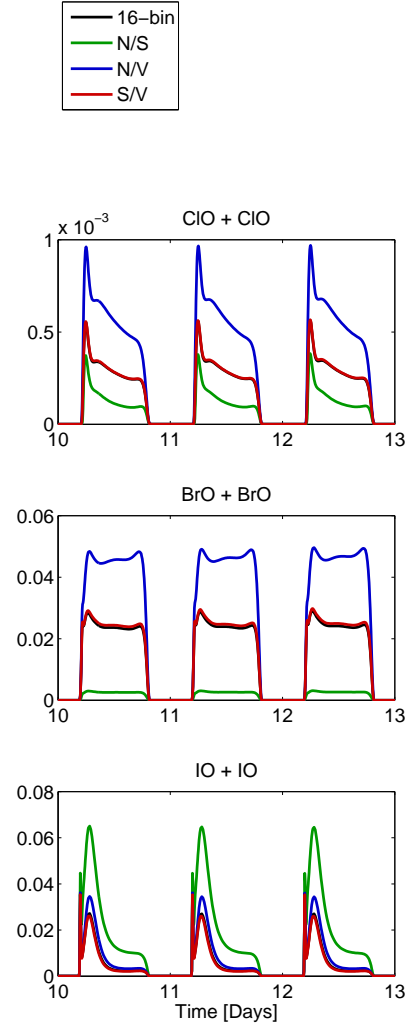
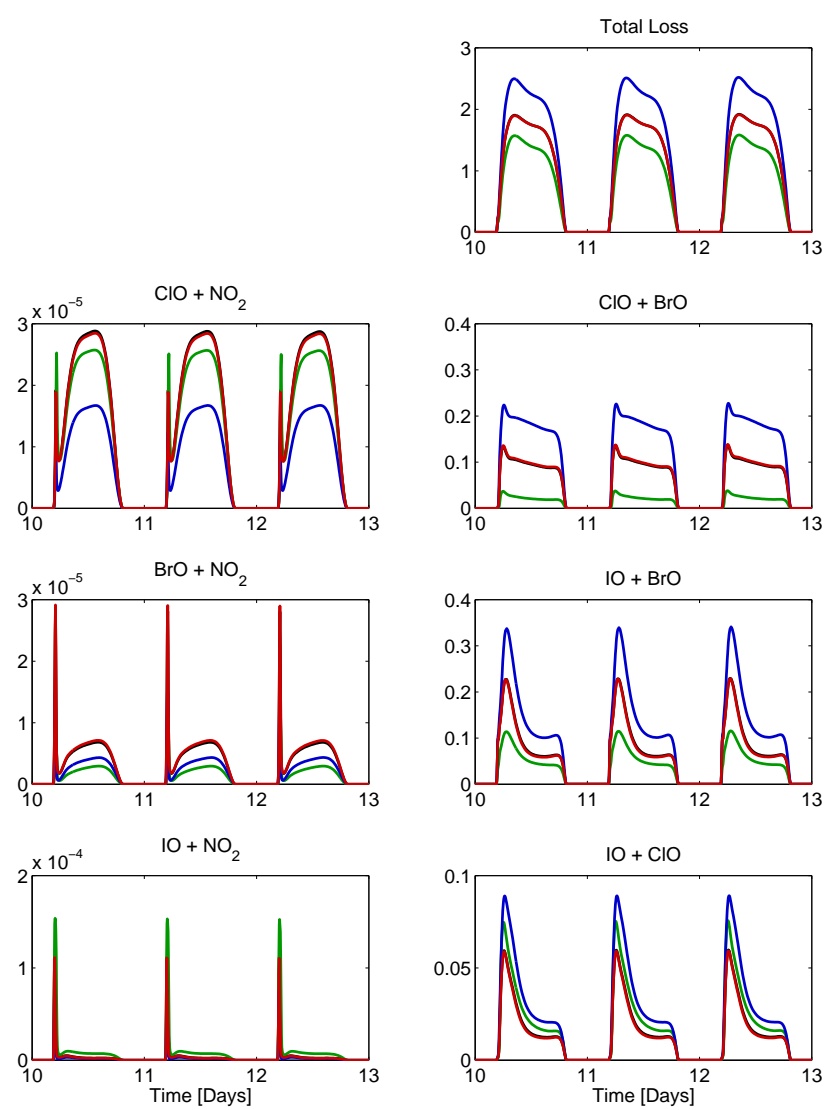

Fig. 2. Comparison of ozone destruction rates (in percentage loss of total ozone per hour) for the 16-bin S/V initialised seasalt mode, and the 1-bin N/S, N/V, and S/V initialised seasalt modes. These are represented by the black, green, blue and red lines, respectively. The seasalt aerosol turnover rate is fixed at 0.57 days (see text).

outside the bounds of the size-bin the particles are moved to the appropriate adjacent size-bin and added to any particles already there. This preserves the total particle number and mass, from which a centre-point radius is calculated for the appropriate size-bin. The size-distributions are recalculated every $5 \mathrm{~min}$ of model time (the internal time-steps of the Rosenbrock solver are allowed to grow up to this limit).

The multi-phase chemistry scheme is based on that of Pechtl et al. (2006), with several updates (see supplementary material: http://www.atmos-chem-phys.net/9/4559/ 2009/acp-9-4559-2009-supplement.pdf). The kinetics of gaseous halogen reactions are the subject of substantial ongoing research, but any changes to the scheme used here will not substantially change the conclusions of the current work. The condensed-phase major ions $\left(\mathrm{H}^{+}-\mathrm{Na}^{+}-\mathrm{NH}_{4}^{+}-\right.$ $\left.\mathrm{HSO}_{4}^{-}-\mathrm{SO}_{4}^{2-}-\mathrm{NO}_{3}^{-}-\mathrm{Cl}^{-}\right)$are treated in a non-ideal manner using PD-FiTE (Topping et al., 2009) to calculate the vapour pressures of $\mathrm{HNO}_{3}, \mathrm{HCl}$ and $\mathrm{NH}_{3}$ as well as the activity coefficients for the dissociation of $\mathrm{HSO}_{4}^{-}$and the aforementioned condensed-species. All other condensedphase species are treated in an ideal manner (as is the above system for solutions with a $\mathrm{pH}$ greater than 7). Midday photolysis rates are taken from Sander and Crutzen (1996), and adjusted for time of day using a simple scheme included with KPP.

The physical properties of the particles are calculated directly from the condensed chemical species. Aerosol "dry" mass (total mass excluding $\mathrm{H}_{2} \mathrm{O}$ ) is calculated as the sum of all condensed-phase species. Dry density is fixed at $2000 \mathrm{~kg} \mathrm{~m}^{-3}$. These dry physical properties are only used for determining the distribution of particles across the size-grid, as described above. The aerosol "wet" mass is the dry mass plus the mass of $\mathrm{H}_{2} \mathrm{O}$. The $\mathrm{H}_{2} \mathrm{O}$ condensed-phase concentration for each size-bin is calculated using the formulation of Zaveri et al. (2005); which uses the same condensed-phase major ions as PD-FiTE. Wet density is calculated using the condensed-phase major ions, which are anion/cation paired to form inorganic solutes with known densities, the relative concentrations of which are determined using the mixing scheme of Reilly and Wood (1969). Using the mass fraction mixing rule of Tang (1997), we can determine an average solution density based on the relative concentrations of these solutes as described in more detail by Topping et al. (2005). These wet physical properties are used for all particle-size determined physical processes, such as condensational particle growth and aerosol turnover rates, as described below. 

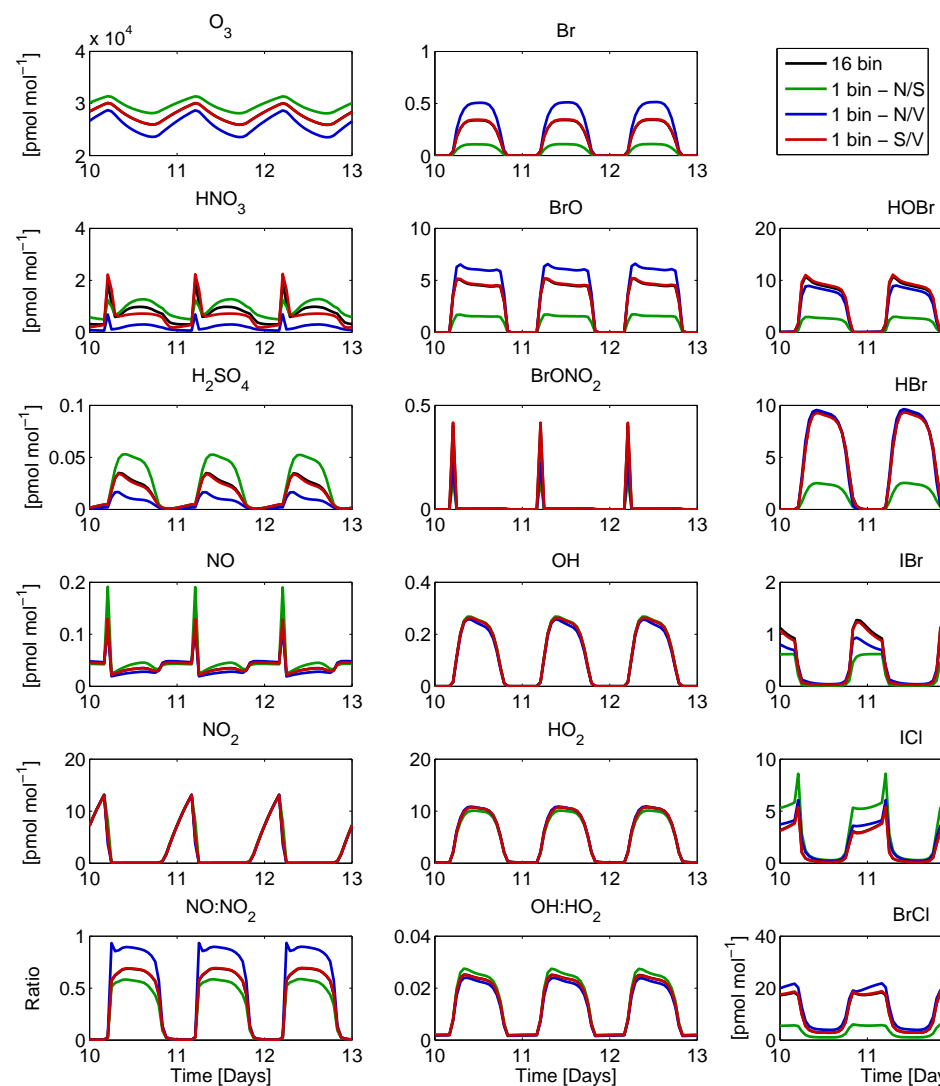
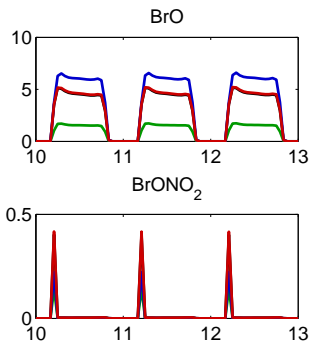

$\mathrm{OH}$
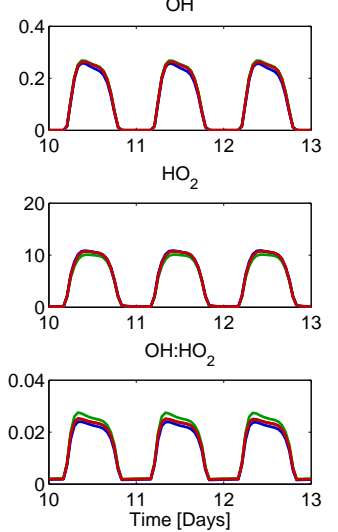
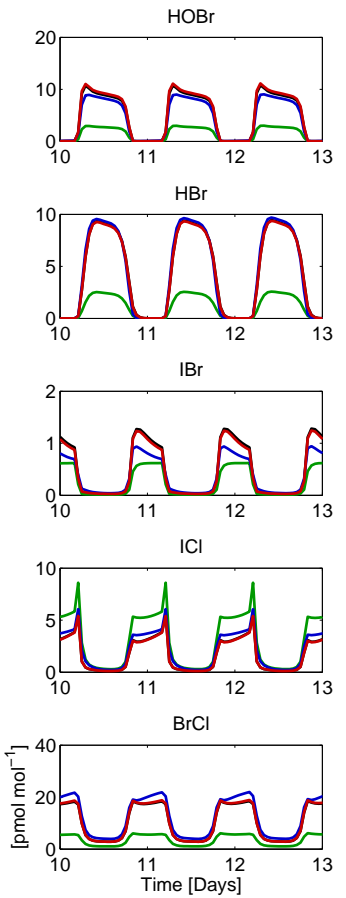
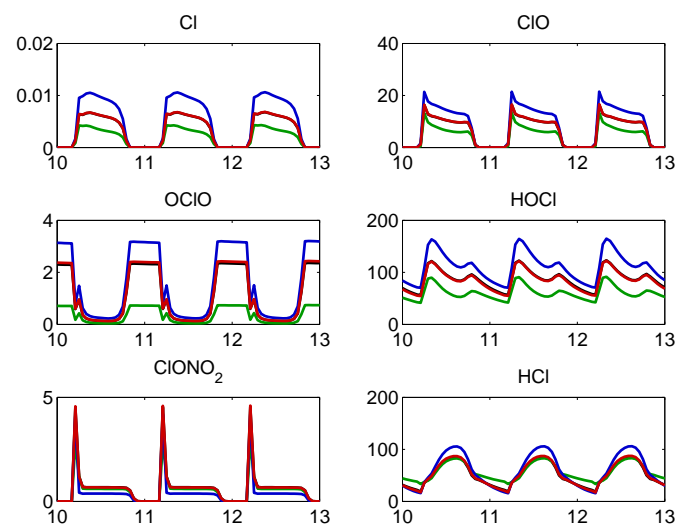

।

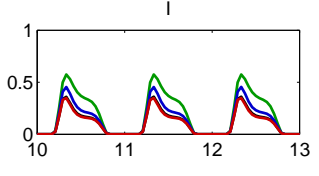

$\mathrm{OIO}$
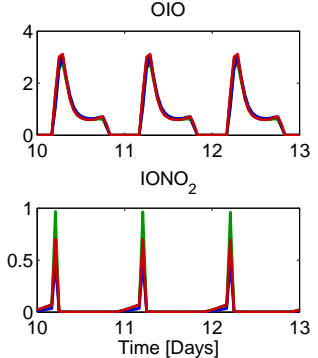
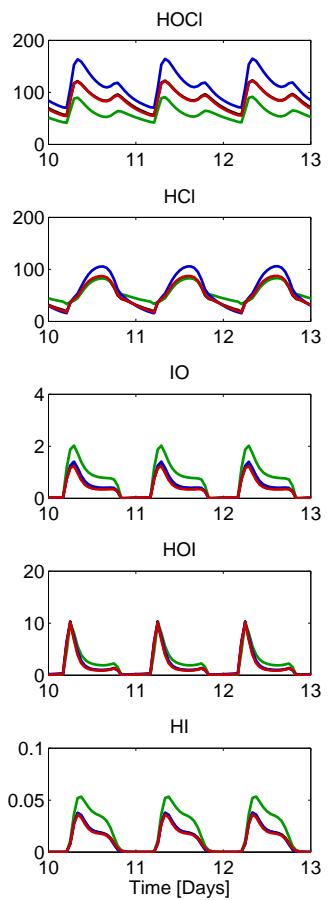

Fig. 3. Comparison of gas-phase mixing ratios for ozone, the major halogen species, and the major $\mathrm{HO}_{\mathrm{x}}$ and $\mathrm{NO}_{\mathrm{x}}$ species for the $16-b i n \mathrm{~S} / \mathrm{V}$ initialised seasalt mode, and the 1-bin N/S, N/V, and S/V initialised seasalt modes. These are represented by the black, green, blue and red lines, respectively. The seasalt aerosol turnover rate is fixed at 0.57 days (see text).

The use of only the major ions for determining the wet density and $\mathrm{H}_{2} \mathrm{O}$ mass is only valid if the mole fraction of these ions is close to unity. In this study both the seasalt and non-seasalt modes are both initialised with compositions which give total "dry" mole fractions of the main ions of $>0.99$ (see below). By the end of the model run this mole fraction has reduced to 0.90 for aerosol particles (both seasalt and non-seasalt) with "wet" radii less than $1 \mu \mathrm{m}$, but has remained at 0.99 for the particles with "wet" radii greater than $1 \mu \mathrm{m}$. This shows that our methods will give reasonable approximations of the actual wet density and $\mathrm{H}_{2} \mathrm{O}$ mass.

Changes in concentration of a gas-phase chemical species $\left(c_{g}\right.$, molecules $\left.\mathrm{cm}_{\text {air }}^{-3}\right)$ due to exchange with the condensedphase are given as (cf. Sander, 1999)

$\frac{\partial c_{g}}{\partial t}=-\sum_{i=1}^{n_{b}}\left[k_{t, i}\left(L_{i} c_{g}-\frac{c_{a, i}}{k_{H} R T}\right)\right]$

where $n_{b}$ is the number of aerosol size-bins. $k_{t, i}$ is the mass transfer coefficient $\left(\mathrm{s}^{-1} \mathrm{~cm}_{\text {air }}^{3} \mathrm{~cm}_{\mathrm{aq}}^{-3}\right), L_{i}$ is the dimensionless liquid water content $\left(\mathrm{cm}_{\mathrm{aq}}^{3} \mathrm{~cm}_{\text {air }}^{-3}\right)$, and $c_{a, i}$ is the concentration of the chemical species in the condensed phase (also in molecules $\mathrm{cm}_{\text {air }}^{-3}$ for computational ease) of bin $i . k_{H}$ is the
Henry constant $\left(\mathrm{mol} \mathrm{m} \mathrm{m}^{-3} \mathrm{~Pa}^{-1}\right)$. The mass transfer for each species is split into its constituent forward and backward reactions and solved in the same time-step as the chemistry (cf. Kerkweg et al., 2007). In keeping with the Moving Centre method, $k_{t, i}$ is calculated only for the "centre" radius of each size-bin, and is defined as (Schwartz, 1986):

$k_{t}=\left(\frac{r^{2}}{3 D_{g}}+\frac{4 r}{3 \bar{v} \alpha}\right)^{-1}$,

where $r$ is the wet droplet radius, $D_{g}$ is gas-phase diffusivity, approximated as $D_{g} \approx \lambda \bar{v} / 3(\lambda$ is mean free path length), mean molecular speed $\bar{v}=\sqrt{8 R T /(M \pi)}$ ( $M$ is molar mass), and $\alpha$ is accommodation coefficient.

Particle formation and coagulation are not treated in the current model. Particle turnover is simulated using a deposition rate, which can be size-dependent or not, matched exactly by an emission rate - so preserving aerosol number. The size-dependent turnover rate, $\left(\tau_{s}\right)^{-1}$, is estimated according to deposition processes:

$\left(\tau_{s}\right)^{-1}=\left(\frac{Z_{\mathrm{mbl}}}{v_{d}}\right)^{-1}+\left(\tau_{\mathrm{wet}}\right)^{-1}$ 

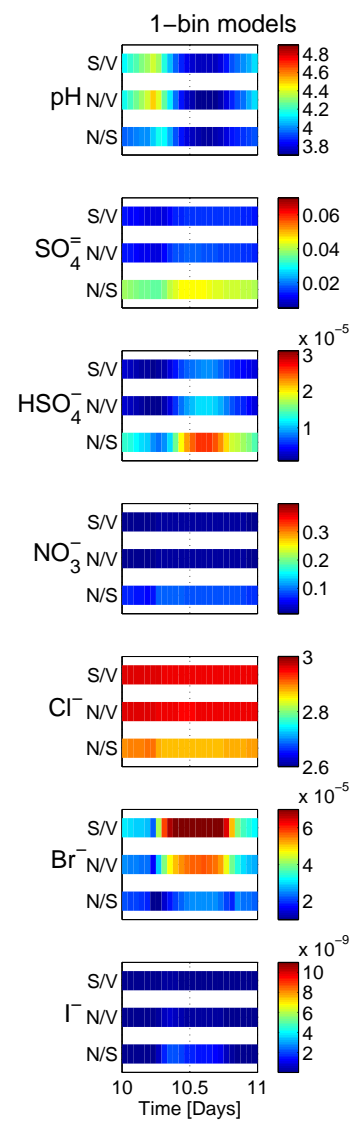
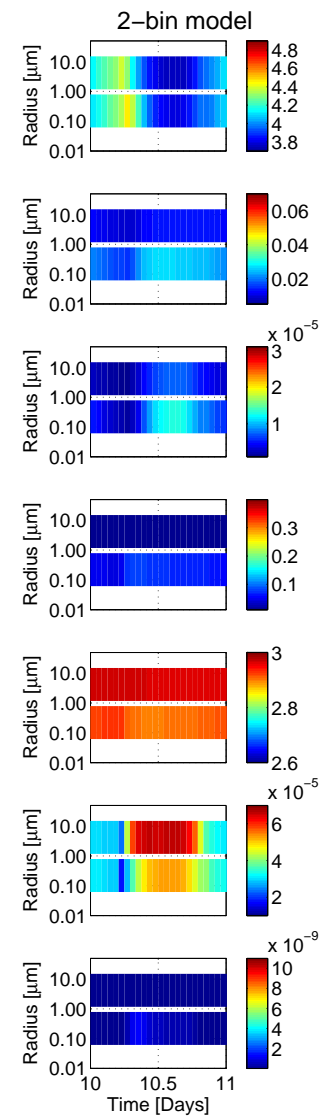
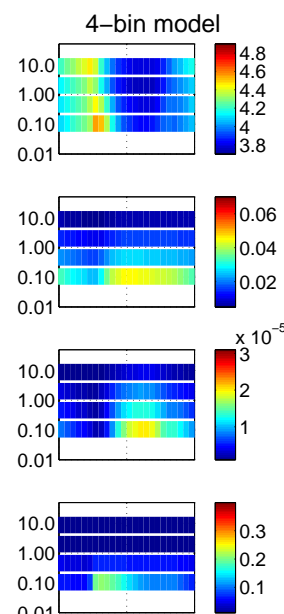

0.0

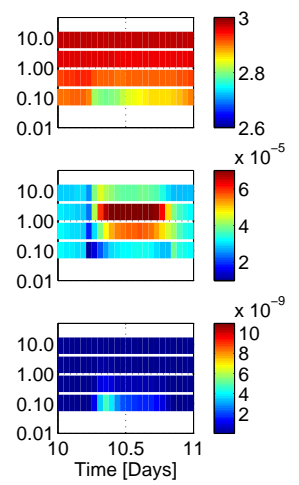

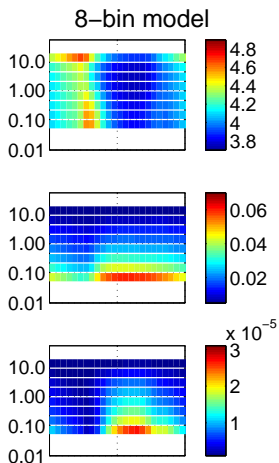
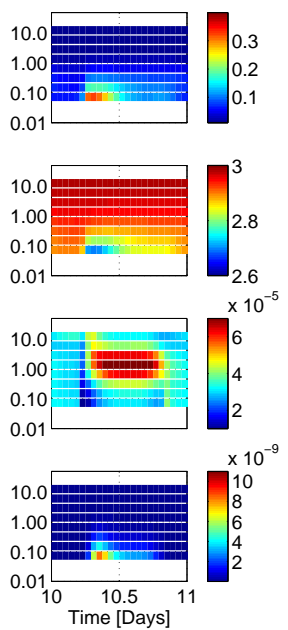
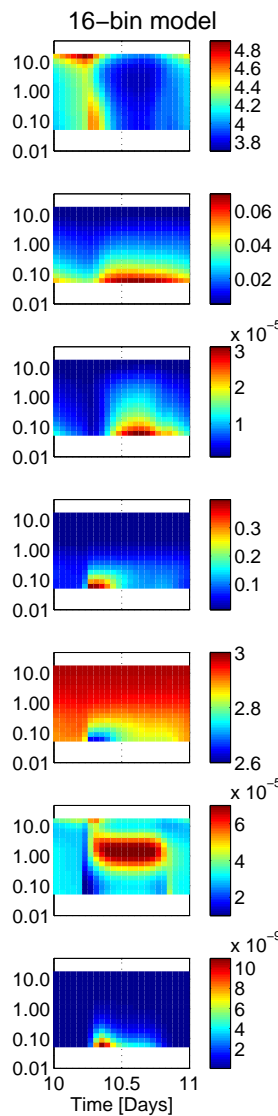

Fig. 4. Comparison of $\mathrm{pH}$ and nitrate, sulphate and halogen molalities ( $\mathrm{mol} \mathrm{kg}_{\mathrm{H}_{2} \mathrm{O}}^{-1}$ ) of the 1-bin $\mathrm{S} / \mathrm{V}, \mathrm{N} / \mathrm{V}$ and N/S initialised, and 2-, 4-, 8-, and 16-bin S/V initialised seasalt modes. The seasalt aerosol turnover rate is fixed at 0.57 days (see text).

after Toyota et al. (2001). $Z_{\mathrm{mbl}}$ is the height of the MBL $(=1000 \mathrm{~m})$, and the size-dependent dry deposition velocity, $v_{d}$, is based on the model of Slinn and Slinn (1980) (assuming $9 \mathrm{~m} \mathrm{~s}^{-1}$ surface wind speed and neutral static stability). The second term in Eq. (3) above represents a first order continuous process, analogous to dry deposition, but used to represent aerosol loss due to other processes, such as wet deposition. It is recognised that wet removal will comprise sporadic events, but this is simply used in order that we can match aerosol deposition rates with emission rates in a consistent manner. The particle lifetime, $\tau_{\text {wet }}$, is set to 8 days after Toyota et al. (2001). Temperature, pressure, and relative humidity are held constant throughout all model runs at values of $285.15 \mathrm{~K}, 1014 \mathrm{hPa}$, and $89.4 \%$, respectively.

The model is initialised with the gas-phase mixing ratios shown in Table 1; of these species only $\mathrm{NH}_{3}$ is fixed. The gas-phase source terms (Table 2) represent two separate processes: emission of gas-phase species from the sea-surface; and the entrainment of air from the free troposphere into the MBL. The source terms for the iodine compounds represent the former process. Entrainment from the free troposphere is used for the ozone source term, at a prescribed velocity of $1.3 \mathrm{~cm} \mathrm{~s}^{-1}$; a fixed ozone mixing ratio in the free troposphere of $40 \mathrm{nmol} \mathrm{mol}^{-1}$ is used, while all other gas-phase species are assumed to have the same mixing ratios as in the MBL. The gas-phase physical removal processes, expressed as velocities, are shown in Table 3. These are used principally to represent deposition at the sea surface, except for the case of ozone, where the loss term is the sum of deposition to the sea and entrainment from the free troposphere. Without a condensed-phase, these representations of physical transport plus conventional odd-hydrogen photochemistry produces a diurnal ozone profile with night-time maxima, and day-time minima, of 34 and $32 \mathrm{nmol} \mathrm{mol-1}$, respectively (not shown).

The non-seasalt mode used in this study is a simple lognormal distribution, with parameters given in Table 4, and has a dry composition of $32 \%\left(\mathrm{NH}_{4}\right)_{2} \mathrm{SO}_{4}, 64 \% \mathrm{NH}_{4} \mathrm{HSO}_{4}$ and $4 \% \mathrm{NH}_{4} \mathrm{NO}_{3}$. For the seasalt mode a pseudo-lognormal, bi-modal, distribution (Porter and Clarke, 1997) linearly scaled to yield $15 \mu \mathrm{g} \mathrm{m}_{\text {air }}^{-3}$ of particulate $\mathrm{NaCl}$ (after Toyota et al., 2001) is chosen. This represents a seasalt loading typical of higher wind-speed conditions close to the sea surface (cf. Graedel and Keene, 1995), chosen in order to exaggerate the magnitude of any size-resolution dependent effects which may occur. The dry composition of the seasalt mode is $99.4317 \% \mathrm{NaCl}, 0.1491498 \% \mathrm{NaBr}, 1.372178 \times 10^{-5} \% \mathrm{NaI}$, 

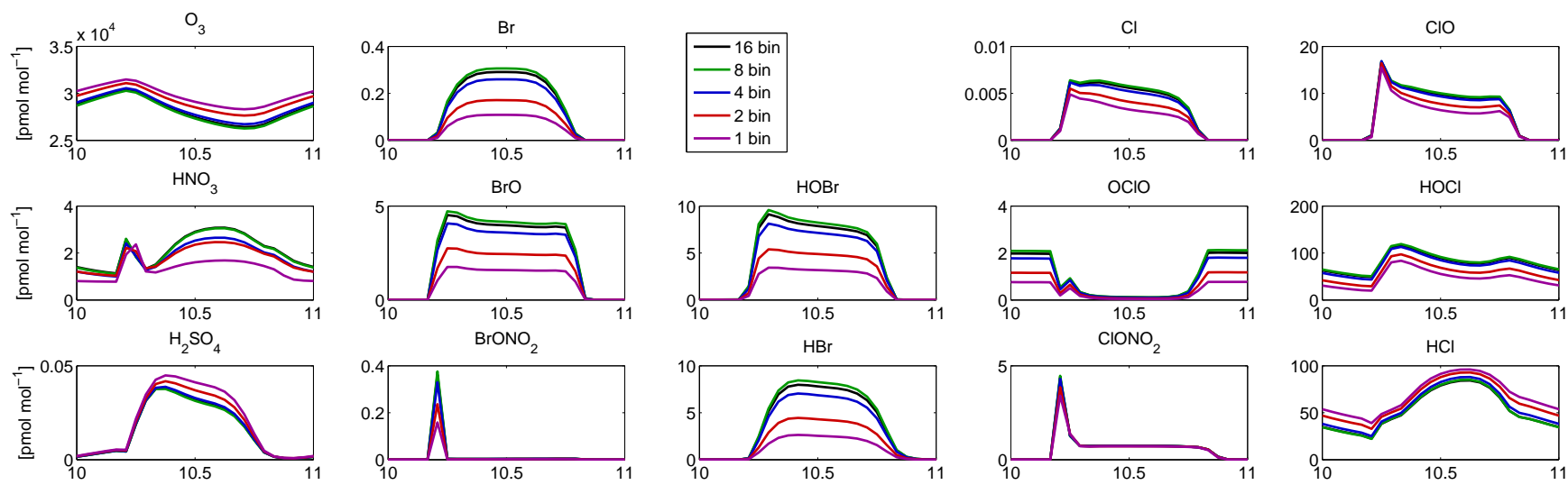

$\mathrm{HOCl}$

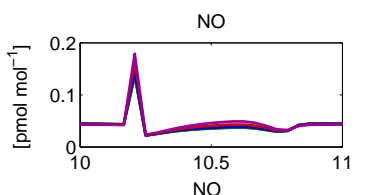

$\mathrm{OH}$

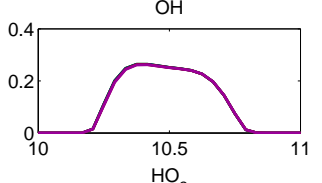

$\mathrm{IBr}$

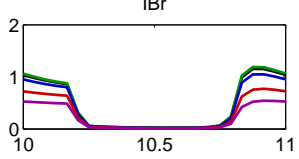

$\mathrm{ICl}$
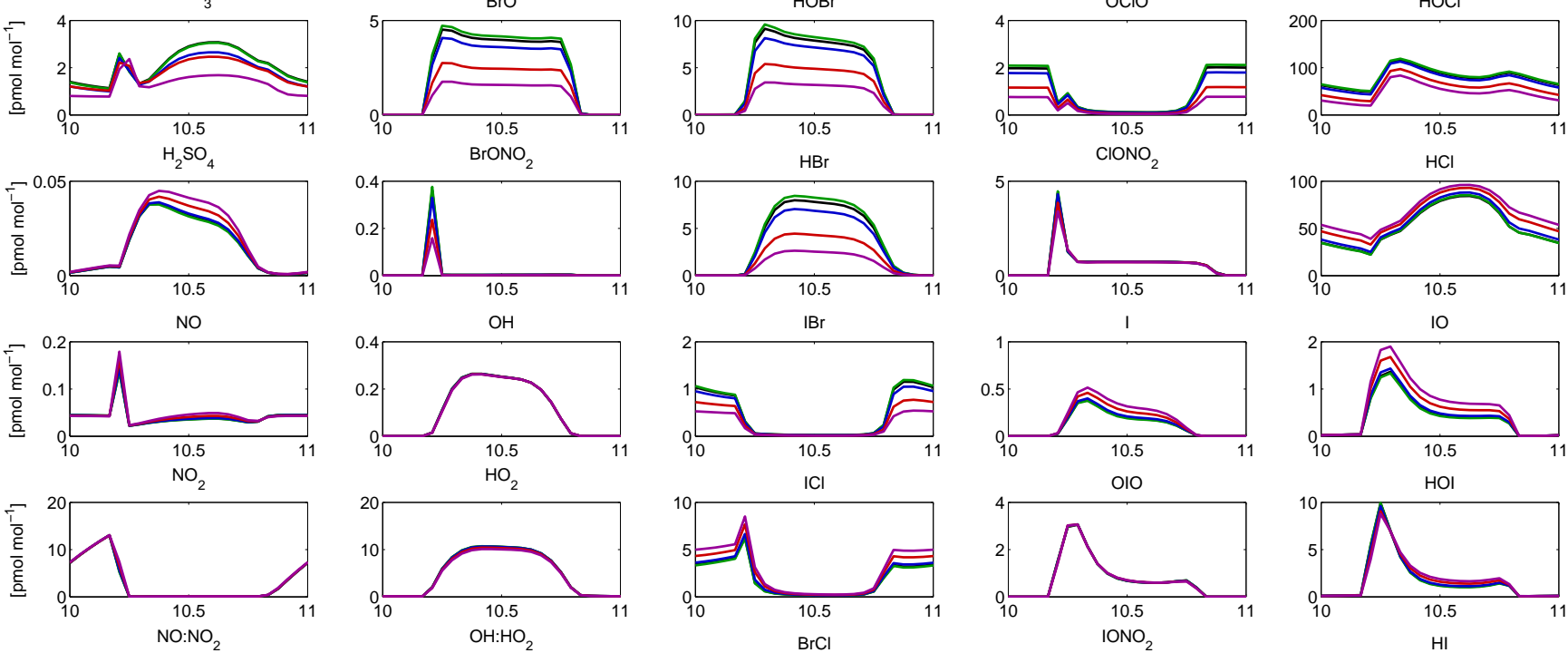

$\mathrm{HO}$
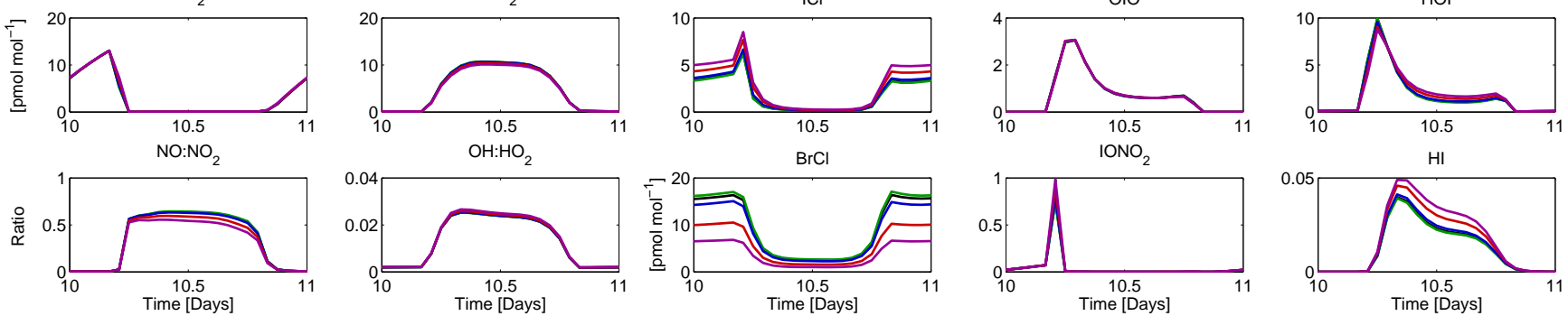

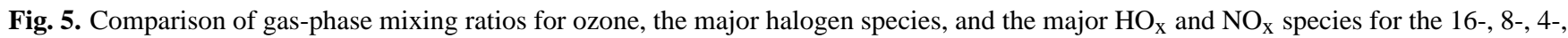
2-, and 1-bin S/V initialised seasalt modes. These are represented by the black, green, blue, red, and purple lines, respectively. The seasalt aerosol turnover rate is calculated on-line for each different size-resolution.

Table 1. Initial gas-phase chemical mixing ratios (given in pmol mol${ }^{-1}$ ).

\begin{tabular}{lr}
\hline Species & mixing ratio \\
\hline $\mathrm{NO}_{2}$ & 20 \\
$\mathrm{HCHO}$ & 300 \\
$\mathrm{PAN}$ & 10 \\
$\mathrm{CO}$ & 70000 \\
$\mathrm{HNO}_{3}$ & 5 \\
$\mathrm{SO}_{2}$ & 90 \\
$\mathrm{CH}_{3} \mathrm{SCH}_{3}$ & 60 \\
$\mathrm{H}_{2} \mathrm{O}_{2}$ & 600 \\
$\mathrm{C}_{2} \mathrm{H}_{6}$ & 500 \\
$\mathrm{HCl}$ & 100 \\
$\mathrm{CH}$ & $2 \mathrm{I}$ \\
$\mathrm{C}_{3} \mathrm{H}_{7} \mathrm{I}$ & 2 \\
$\mathrm{NO}$ & 1 \\
$\mathrm{NH}_{3}$ & 10 \\
$\mathrm{O}_{3}$ & 50 \\
\hline
\end{tabular}

${ }^{\mathrm{a}}$ after von Glasow et al. (2002); ${ }^{\mathrm{b}}$ estimated.
Table 2. Gas-phase emission fluxes, $J_{e, g}$, in $\mathrm{cm}^{-2} \mathrm{~s}^{-1}$. The $\mathrm{O}_{3}$ flux is calculated from a free troposphere mixing ratio of 40 $\mathrm{nmol} \mathrm{mol}{ }^{-1}$ and entrainment velocity of $1.3 \mathrm{~cm} \mathrm{~s}^{-1}$.

\begin{tabular}{lc}
\hline Species & $J_{e, g}$ \\
\hline $\mathrm{O}_{3}$ & $1.326 \times 10^{12}$ \\
$\mathrm{NO}$ & $1.5 \times 10^{9}$ \\
$\mathrm{CH}_{3} \mathrm{SCH}_{3}$ & $2 \times 10^{9}$ \\
$\mathrm{CH}_{3} \mathrm{I}$ & $6 \times 10^{6}$ \\
$\mathrm{C}_{3} \mathrm{H}_{7} \mathrm{I}$ & $1 \times 10^{7}$ \\
$\mathrm{CH}_{2} \mathrm{CII}$ & $2 \times 10^{7}$ \\
$\mathrm{CH}_{2} \mathrm{I}_{2}$ & $3 \times 10^{7}$ \\
$\mathrm{CH}_{2} \mathrm{BrI}$ & $2 \times 10^{7}$ \\
$\mathrm{I}_{2}$ & $40 \times 10^{7}$ \\
\hline
\end{tabular}

${ }^{a}$ Zafiriou et al. (1980) ${ }^{b}$ Quinn et al. (1990); Sander and Crutzen (1996) ${ }^{c}$ Vogt et al. (1999) ${ }^{d}$ estimated after Carpenter et al. (1999) e estimated after McFiggans et al. (2002) 

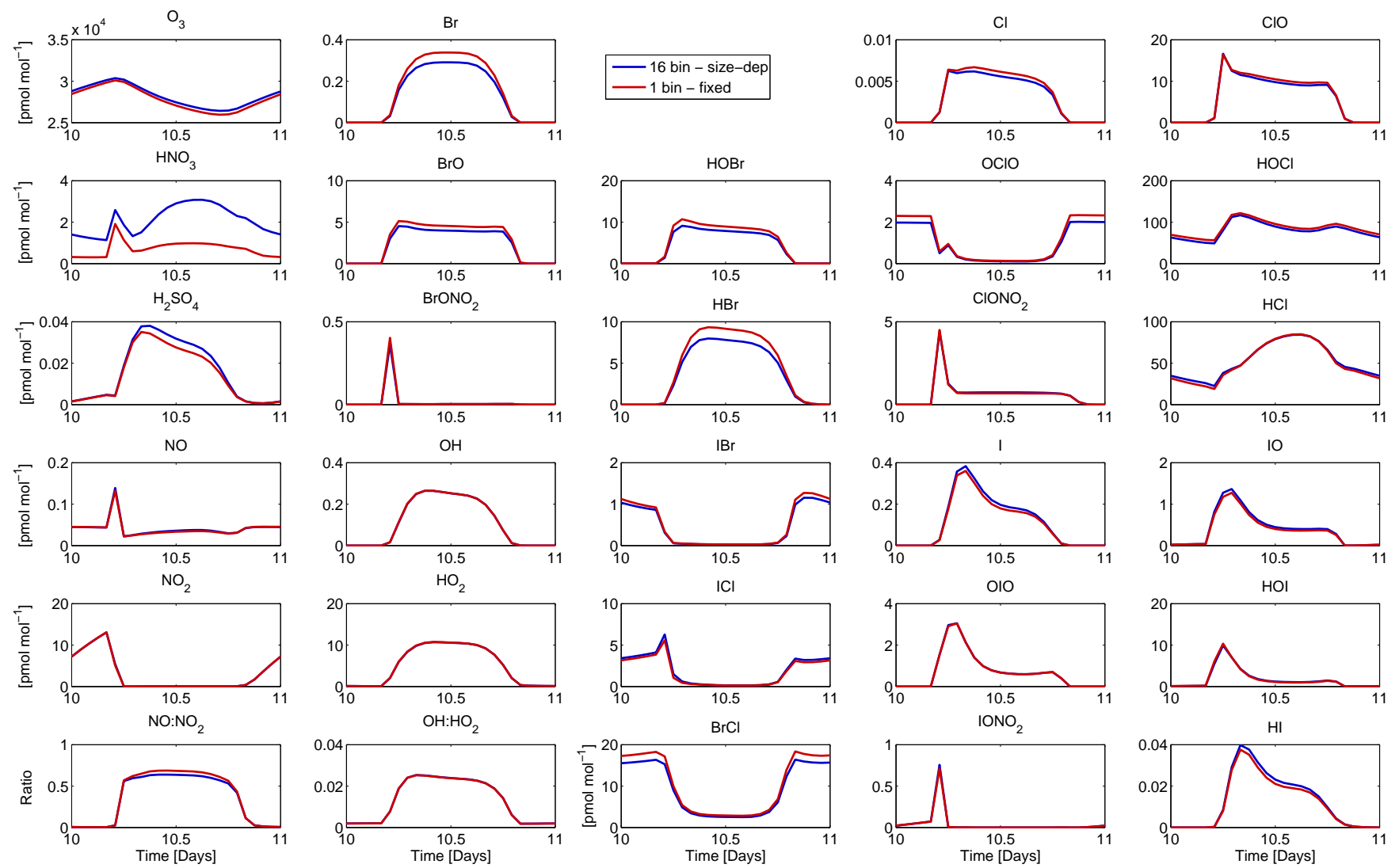

Fig. 6. Comparison of gas-phase mixing ratios for ozone, the major halogen species, and the major $\mathrm{HO}_{\mathrm{x}}$ and $\mathrm{NO}_{\mathrm{x}}$ species for the 16-, and 1-bin S/V initialised seasalt modes. These are represented by the blue and red lines, respectively. The seasalt aerosol turnover rate is calculated on-line for the 16-bin seasalt mode, for the 1-bin seasalt mode the turnover rate is fixed at 0.57 days.

$4.812565 \times 10^{-5} \% \mathrm{NaIO}_{3}$, and $0.4176193 \% \mathrm{NaHCO}_{3}$. Organic aerosol constituents are not included in this study, but MANIC may be expanded to incorporate treatment of representative organic material on the availability of the extended PD-FiTE thermodynamic module (Topping et al., 2009). The condensed-phase chemistry scheme is simplified by lumping together all (unreactive) cations as $\mathrm{Na}^{+}$(von Glasow et al., 2002). Similarly the initial composition of the seasalt mode has been simplified by not including sulphate (which is assumed to be unreactive), although sulphate is still allowed to condense onto the this mode. These simplifications, however, will not affect the conclusions of this study.

To generate the various discrete aerosol distributions used from these continuous distributions the given number distributions are first discretised into 128 bins. The (dry) surface area and volume for each bin are then determined and recombined to create the 1-, 2-, 4-, 8-, or 16-bin distributions. Only two of the three moments (number, surface area, and mass) of the aerosol-distribution can be preserved when calculating these reduced resolution distributions. Thus there are three possible initialisation types: those preserving number and volume (N/V); number and surface area (N/S); and surface area and volume $(\mathrm{S} / \mathrm{V})$. The differences in the seasalt size- distribution for each of these initialisation types are shown in Fig. 1 and given in Table 5. The differences between initialisations for the 16-bin distributions are of the order of a few percent, and so we shall treat these as an accurate reference representation of the continuous distribution. As the size-resolution of aerosol phase is reduced these discrete representations become less realistic. For the N/V initialisation, the seasalt dry surface area is too large and it is expected in model runs using this initialisation that chemical exchange between the gas- and condensed-phase would be too fast. For the N/S initialisation the seasalt dry volume is too low, reducing the total aerosol mass. It may be expected that this will reduce the halogen source from the condensed-phase. For the S/V initialisation the total particle number is too low; however this has no influence on the processes under investigation in the current work. It may therefore be expected that this will have no effect on the model runs.

All model runs are started with the initial conditions described above, and given 10 days spin-up time, which is the order of time scale required for all processes to stabilise to give a steady state diurnal profile. Whilst it is recognised that this is a somewhat unrealistic tropospheric residence time, it is required because all processes initiate a perturbation at 


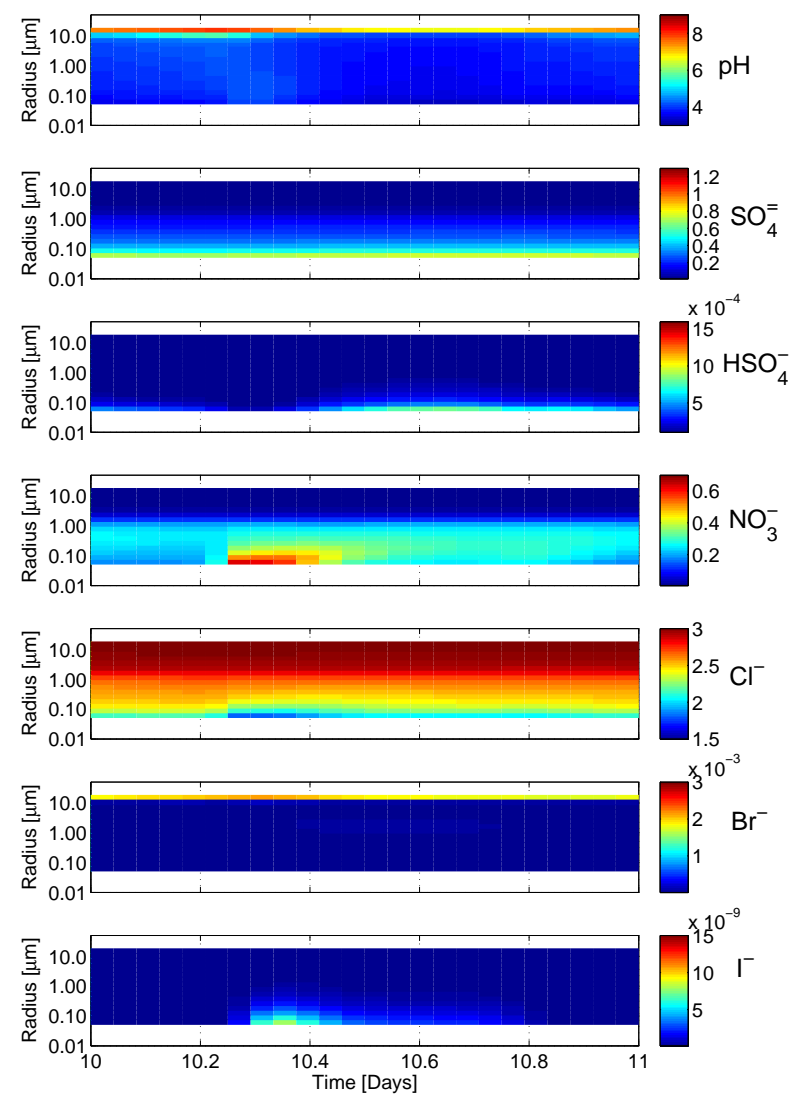

Fig. 7. $\mathrm{pH}$ and nitrate, sulphate and halogen molalities $\left(\mathrm{mol} \mathrm{kg}_{\mathrm{H}_{2} \mathrm{O}}^{-1}\right)$ for the 16-bin $\mathrm{S} / \mathrm{V}$ initialised seasalt mode. The seasalt aerosol turnover rate is calculated on-line.

time $t=0$, hence the model initialisations are far from steadystate. This is not the case in the real atmosphere, where a steady-state would be achieved in a much shorter time scale. The trends in all species are similar after, say, 3 or 4 days; but full stability in the results is exhibited after 10 days.

For all simulations described below a 1-bin, S/V initialised, non-seasalt mode, with a size-independent turnover rate of 7 days $^{-1}$ is used. Model runs have been made to examine the influence of size-resolution in the non-seasalt model on the testcase results. For these clean marine conditions, however, the resolution dependence of this mode is minimal (not shown), and so for the discussion below focuses purely on the seasalt mode.

\section{Results and discussion}

\subsection{Aerosol initialisation, size resolution and chemistry interactions}

In Figs. 2 and 3 the percentage ozone lost via autocatalytic halogen cycles, and gas-phase mixing ratios of key species are respectively shown for the fixed aerosol-turnover sce-
Table 3. Gas-phase loss velocities, $v_{d, g}$, in $\mathrm{cm} \mathrm{s}^{-1}$. Principally describing deposition at the sea surface (after Kanakidou, M., personal communication, 2008), ozone loss also includes entrainment to the free troposphere, the velocity of which has been listed separately to the ozone deposition velocity (the total ozone loss velocity being the sum of these two).

\begin{tabular}{ll}
\hline Species & $v_{d, g}$ \\
\hline $\mathrm{O}_{3}$ (entrainment) & 1.3 \\
$\mathrm{O}_{3}$ (deposition) & 0.15 \\
$\mathrm{H}_{2} \mathrm{O}_{2}$ & 0.5 \\
$\mathrm{NO}_{3}$ & 1 \\
$\mathrm{~N}_{2} \mathrm{O}_{5}$ & 1 \\
$\mathrm{HNO}_{3}$ & 0.7 \\
$\mathrm{HNO}_{4}$ & 0.5 \\
$\mathrm{HCHO}$ & 0.5 \\
$\mathrm{ROOH}_{\mathrm{HCl}}$ & 0.5 \\
$\mathrm{HOCl}$ & 2 \\
$\mathrm{HBr}$ & 0.2 \\
$\mathrm{HOBr}$ & 2 \\
$\mathrm{CH}_{3} \mathrm{SOCH}$ & 0.2 \\
$\mathrm{DMSO}_{2}$ & 0.5 \\
$\mathrm{SO}_{2}$ & 0.5 \\
$\mathrm{H}_{2} \mathrm{SO}_{4}$ & 0.87 \\
$\mathrm{HI}$ & 1 \\
$\mathrm{HOI}$ & 1 \\
$\mathrm{INO}_{3}$ & 1 \\
$\mathrm{INO}_{2}$ & 1 \\
$\mathrm{HCOOH}$ & 1 \\
\hline
\end{tabular}

Table 4. Parameters for the non-seasalt aerosol distribution used in study. $N_{\text {tot }}$ is in $\mathrm{cm}^{-3}$ and $R_{N}$ in $\mu \mathrm{m}$. The log-normal particle size distribution is calculated according to $\frac{d N(r)}{d r}=\frac{N_{\text {tot }}}{\ln \sigma \sqrt{2 \pi}} \times \exp \left(-\frac{\left(\ln r-\ln R_{N}\right)^{2}}{2(\ln \sigma)^{2}}\right)$.

\begin{tabular}{lccc}
\hline Mode & $N_{\text {tot }}$ & $R_{N}$ & $\sigma$ \\
\hline non-seasalt & 237 & 0.088 & 1.29 \\
\hline
\end{tabular}

nario showing a comparison of the three different initialisation techniques for the 1-bin seasalt mode and the S/V initialised 16-bin seasalt mode (all model runs are made with the same S/V initialised 1-bin non-seasalt mode). The differences in gas-phase composition between the different initialisations methods for the 16-bin seasalt mode are minor $(<2 \%$, not shown), supporting the assumption that using a 16-bin resolution is a reasonable representation of the continuous distribution.

The differences in gas-phase chemistry between the S/V initialised 1-bin and 16-bin seasalt modes are generally minor (Fig. 3), with ozone levels within the 1-bin model $\approx 0.05 \%$ greater than those of the 16-bin model. The 
observed changes in the gas-phase chemistry for the N/S initialised seasalt mode are, as may be expected from a lower seasalt mass loading: decreased gaseous mixing ratios of chlorine and bromine compounds (due to the lower mass of the seasalt source for these compounds) and increased levels of gaseous iodine compounds (due to the reduced size of the aerosol sink for iodine). These changes lead to a slight decrease in ozone destruction (ozone levels are $\approx 2 \%$ higher). Likewise the changes in gas-phase chemistry for the N/V initialised seasalt mode are, as might be expected from increasing the surface-area across which the gas and condensed components interact: levels of gas-phase active chlorine and bromine compounds are higher - owing to increased rates of outgassing from the seasalt source term and also higher rates of heterogeneous processing. Active iodine compound levels are also slightly increased, again resulting from the increased processing rates. These changes lead to a marked increase in ozone destruction (ozone levels are $\approx 5 \%$ lower).

The size-dependence of the major components of the seasalt mode is shown in Fig. 4. Of the 1-bin seasalt representations it is evident that the $\mathrm{S} / \mathrm{V}$ and $\mathrm{N} / \mathrm{V}$ initialisations best replicate the composition of the bulk mode of the higher resolution seasalt modes. As the size-resolution of the seasalt mode is increased the development of size-dependent structures in the seasalt composition become apparent. This is distinguishable in the 4-bin model, but best resolved in the 8- and 16-bin model runs. The developing features of the size-dependent composition are as expected; with the highest mixing ratios of those species which condense from the gas-phase (i.e. sulphuric and nitric acids, and iodine) in the smallest particles, while those species whose main sourceterm is the seasalt mode (i.e. chlorine) are most concentrated in the largest particles. In this context bromine is a special case - its main source term is the seasalt mode; but, once a steady state has been reached, the bromine content of the gas-phase is greater than that of the condensed-phase. This gas-phase bromine reservoir reinforces the condensed-phase source term at the centre of the seasalt distribution, leading to a maximum in bromine mixing ratios during the day at these sizes of the distribution. This distribution pattern of bromine is only observed in the size-independent turnover scenario. When more realistic turnover rates are used these, as will be shown below, dominate the distribution of bromine across the particle size-range.

Gas-phase nitric acid mixing ratios are not so well captured using the 1-bin seasalt modes, even when using the S/V initialisation (Fig. 3). However this discrepancy disappears when seasalt modes consisting of 2 or more bins are used (not shown). It is postulated that this difference occurs because the uptake of $\mathrm{HNO}_{3}$ is strongly dependent on the acidity of the solution, and in the higher resolution seasalt modes is slowed by increasing acidity of the smallest seasalt particles (Fig. 4). In the 1-bin model, however, the bulk of the seasalt mode absorbs the increase in acidity, so that the uptake of $\mathrm{HNO}_{3}$ is not slowed.
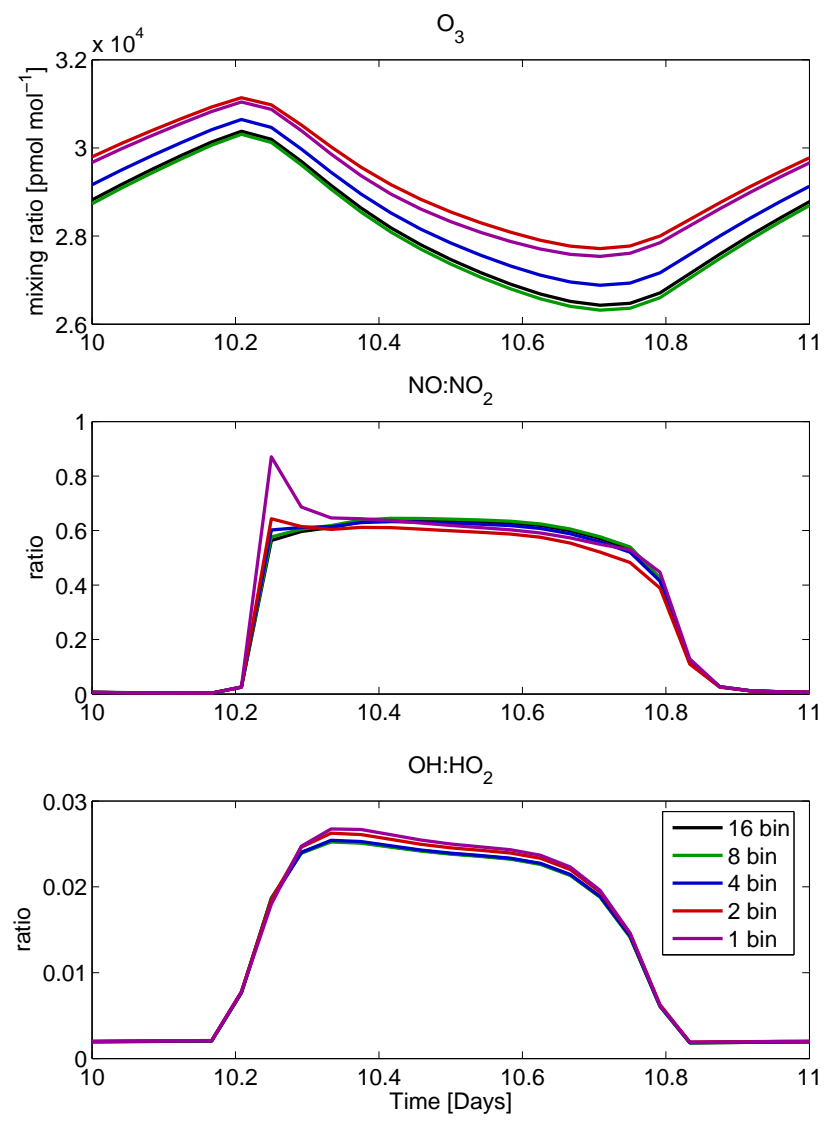

Fig. 8. Comparison of the gas-phase mixing ratio for ozone, and the $\mathrm{NO}: \mathrm{NO}_{2}$ and $\mathrm{OH}: \mathrm{HO}_{2}$ ratios for the the 16-, 8-, 4-, 2-, and 1-bin $\mathrm{N} / \mathrm{V}$ initialised seasalt modes. These are represented by the black, green, blue, red, and purple lines, respectively. The seasalt aerosol turnover rate is calculated on-line for each different size-resolution.

The differences in gas-phase chemistry between the different 1-bin aerosol initialisations, and the similarity between the 1-bin S/V and 16-bin models, shows the importance of capturing the important physical characteristics of the aerosol phase. This is more important than capturing the size-resolution of the condensed-phase chemistry for the species important to halogen cycling. However, the differences observed in the gas-phase HNO3 mixing ratios between the 1-bin S/V and 16-bin models suggest that sizeresolved chemistry is important for acid-uptake by the seasalt mode.

\subsection{Aerosol microphysics, size resolution and chemistry interactions}

Model behaviour with more atmospherically realistic sizedependent turnover rates for the seasalt mode is now investigated. Figure 5 shows the gas-phase halogen compositions for the S/V-initialised 1- to 16-bin seasalt modes, where the seasalt turnover rates are calculated on-line using 

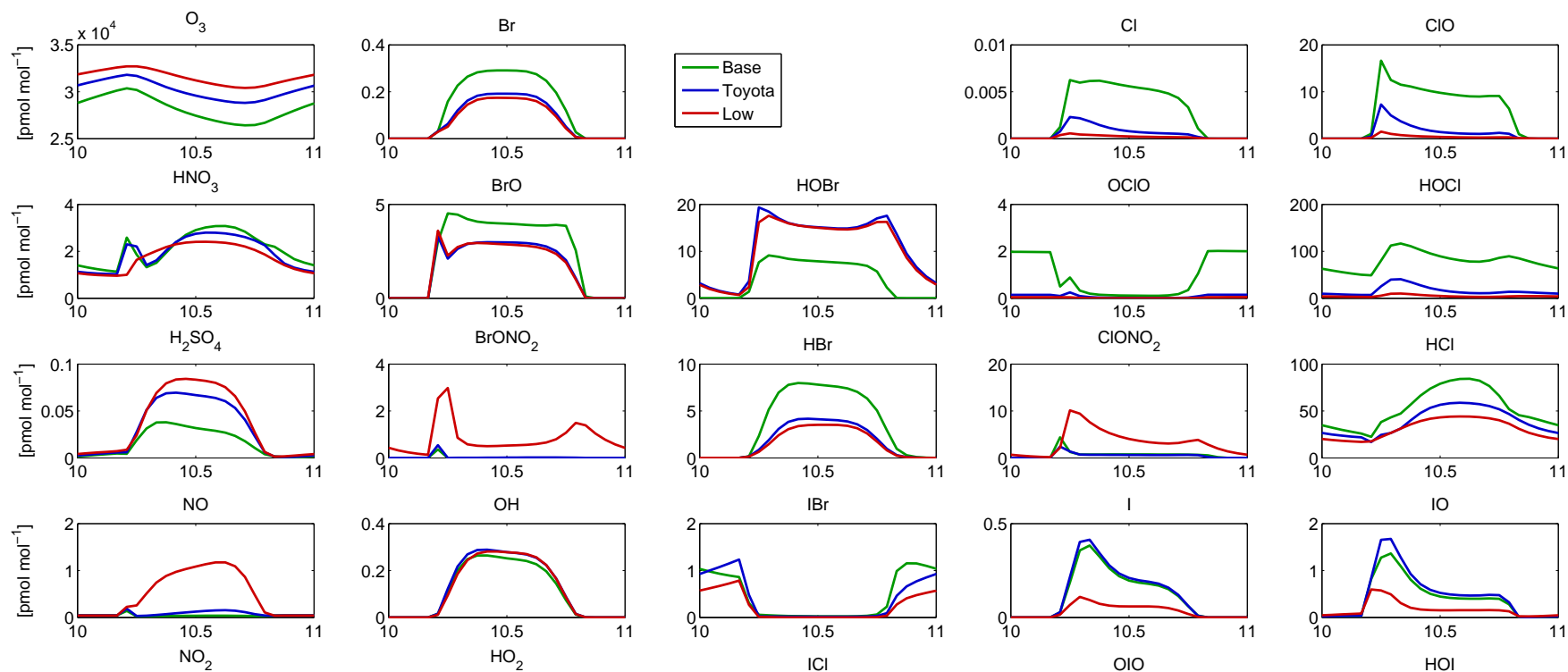

।
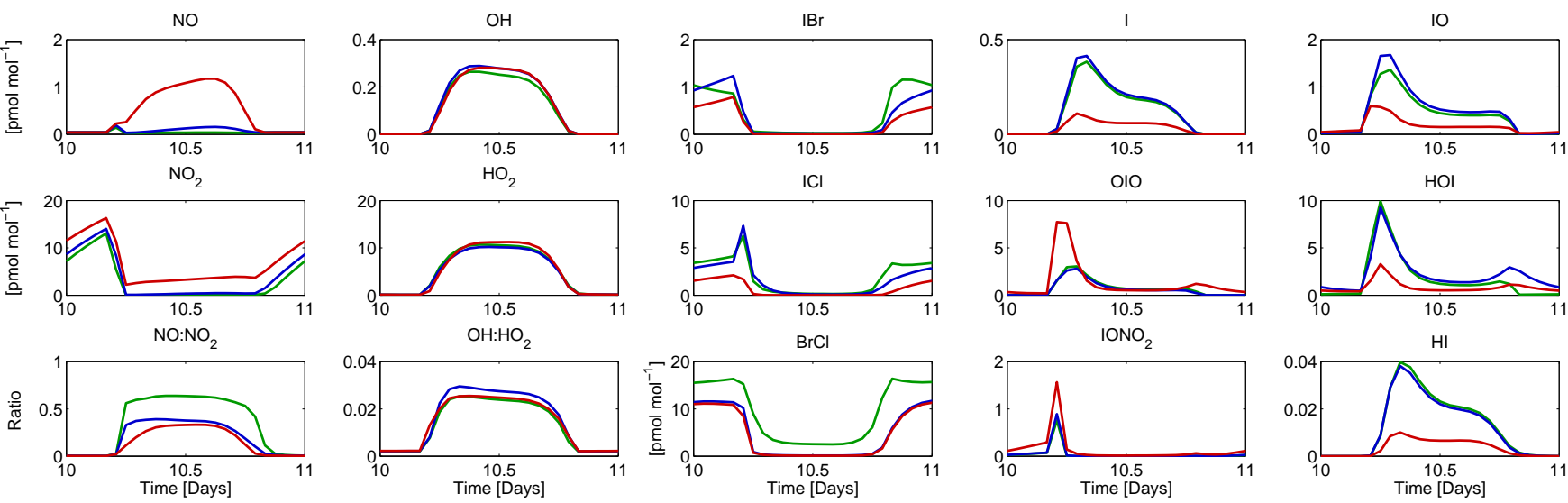

Fig. 9. Comparison of gas-phase mixing ratios for ozone, the major halogen species, and the major $\mathrm{HO}_{\mathrm{x}}$ and $\mathrm{NO}_{\mathrm{x}}$ species for the 16 -bin $\mathrm{S} / \mathrm{V}$ initialised seasalt mode using the Base, Toyota, and Low accommodation coefficient settings. These are represented by the green, blue and red lines, respectively. The seasalt aerosol turnover rate is calculated on-line.

Eq. (3). Ozone destruction is generally less for the lower resolution models - as are bromine and chlorine compound levels (while iodine compound levels are higher). This general trend can be attributed to the decrease in the bulk seasalt turnover rates with decreasing size-resolution (Table 6). This relationship breaks down for the 8 - and 16-bin models, but is consistent across the rest of the resolution range.

For this reason a fixed turnover lifetime of 0.57 days was used for the studies presented in Sect. 3.1 - based on the volumetrically averaged turnover rate of the 16-bin model. Comparison of the 1-bin seasalt model using this fixed turnover lifetime with the 16-bin seasalt model using size-dependent turnover rates calculated online, demonstrates that this is a reasonable approach - as there are few differences between the gas-phase chemistry of these two models (Fig. 6). There is a lower flux of reactive halogen compounds from the 16-bin represented seasalt mode than the 1-bin represented seasalt mode, because the turnover rate of the smallest seasalt particles is decreased. These smallest particles become more acidic, with higher molalities of sulphuric and nitric acids (Fig. 7). But, because they do not remove these acids from the gas-aerosol system as quickly as the fixed turnover rate models, or add extra chlorine and bromine as quickly, the gas-phase $\mathrm{H}_{2} \mathrm{SO}_{4}$ and $\mathrm{HNO}_{3}$ mixing ratios are higher, and the halogen species mixing ratios lower. It is also observed that composition gradients across the particle size-range now dominate any diurnal-variations (Fig. 7). The rapid turnover of the largest particles (which have wet radii of $34 \mu \mathrm{m}$ and lifetimes of $1.7 \mathrm{~h}$ ) is the dominate process determining their chemical composition, far more so than gas-aerosol mass transfer. Because of this they never equilibrate with the gas-phase and remain alkaline, maintaining high $\mathrm{Br}^{-}$and low $\mathrm{SO}_{4}^{2-}$ levels. The short lifetime of these particles also emphasies the diurnal variation in their $\mathrm{pH}$, as aerosol turnover during the night replaces aerosol which was acidified during the day. Diurnal variations in seasalt aerosol $\mathrm{pH}$ for particles with diameters up to $21 \mu \mathrm{m}$ have already been measured (Pszenny et al., 2004); so it is likely that, if the size range of these instruments was increased, that they would be able to resolve the changes in acidity predicted by our model.

Large scale models tend to preserve aerosol number and volume, as for cloud processes the number of $\mathrm{CCN}$ is very important. To illustrate the effect on gas-phase chemistry this could have with the lower size-resolutions necessary for a large-scale model we have plotted $\mathrm{O}_{3}$ mixing ratio, and 


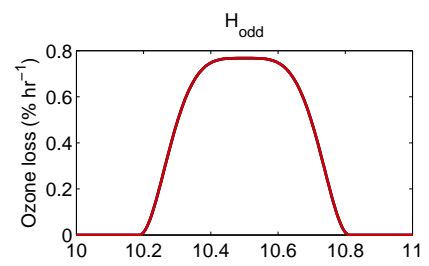

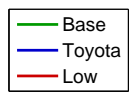
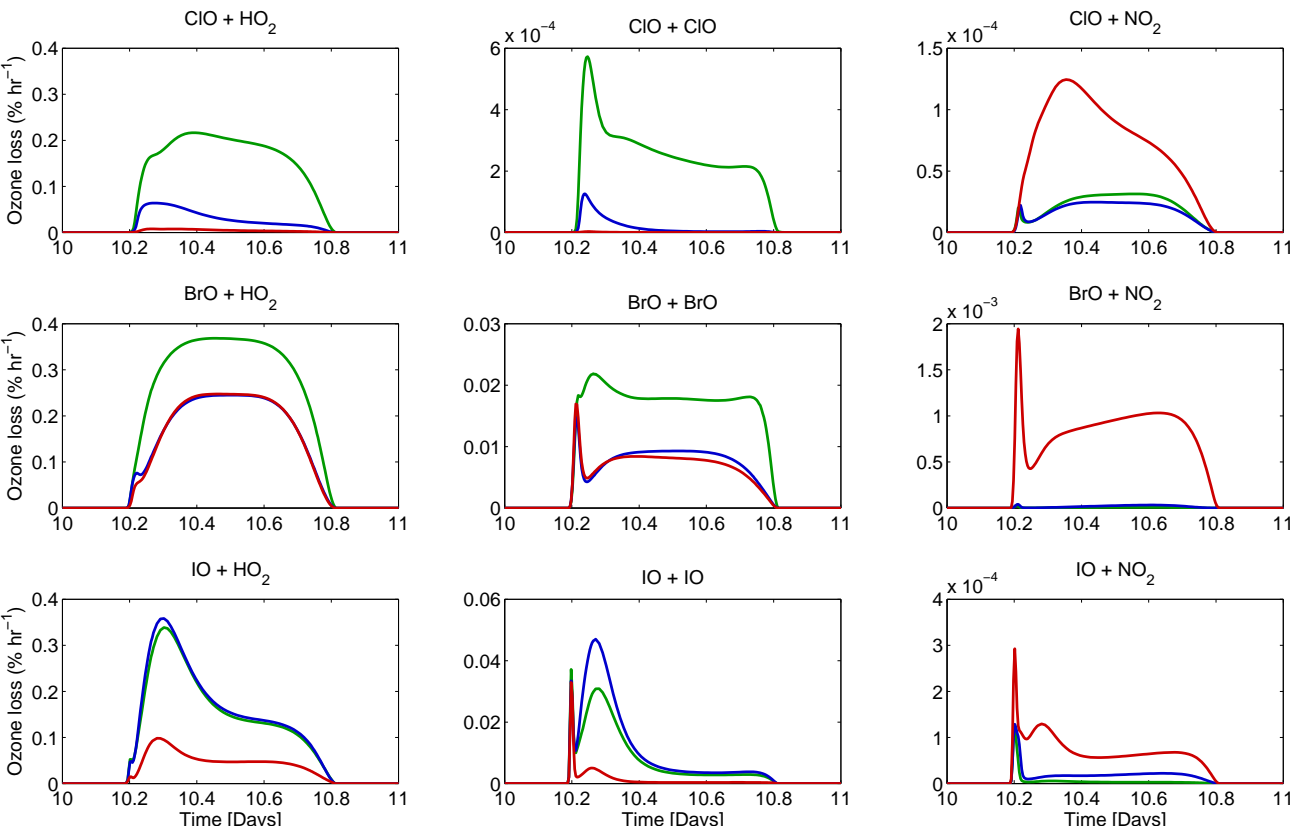
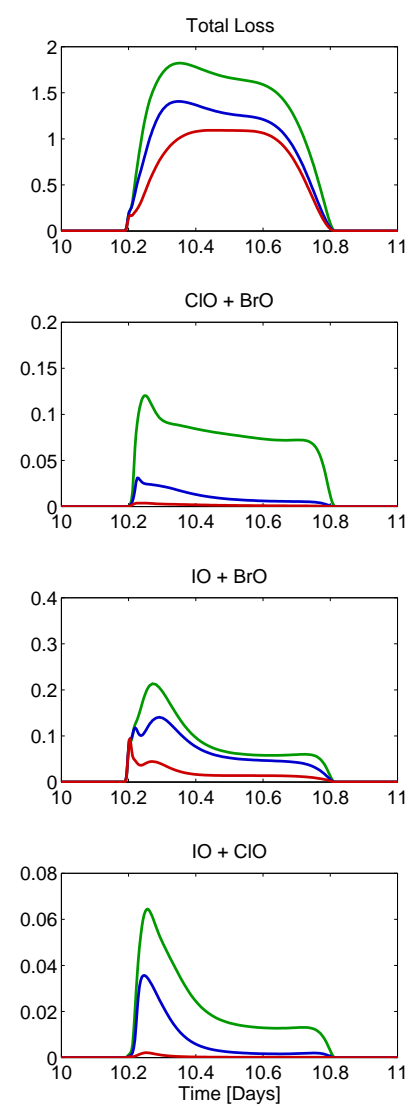

Fig. 10. Comparison of ozone destruction rates (in percentage loss of total ozone per hour) for the 16-bin S/V initialised seasalt mode using the Base, Toyota, and Low accommodation coefficient settings. These are represented by the green, blue and red lines, respectively. The seasalt aerosol turnover rate is calculated on-line.

NO: $\mathrm{NO}_{2}$ and $\mathrm{OH}: \mathrm{HO}_{2}$ ratios for the 1- to 16-bin N/V initialised model runs (Fig. 8). Ozone loss has, as for the $\mathrm{S} / \mathrm{V}$-initialisations, reduced for the lower-resolution models. The $\mathrm{OH}: \mathrm{HO}_{2}$ ratio remains fairly constant for all model resolutions. In the lower resolution models the $\mathrm{NO}: \mathrm{NO}_{2}$ ratio has a pronounced peak at dawn, due to increased NO levels for these models (although $\mathrm{NO}_{\mathrm{x}}$ levels remain low in absolute terms for all model resolutions).

The differences in gas-phase chemistry between the 1-bin and 16-bin models using on-line calculated aerosol turnover rates illustrates the need to use a high size-resolution in order to treat such physical processes accurately. Conversely the similarity in gas-phase chemistry between the 1-bin model, which uses the bulk-averaged turnover rate calculated from the 16-bin model, and the 16-bin model itself demonstrates that the size resolution of the chemistry is less important than the size resolution of the physical processes.

\subsection{Halogen activation cycles and their impacts}

Halogen activation cycles depend on the exchange of halogen species between the gas- and condensed-phases; the uptake rates of gas-phase species onto the condensed-phase are con- trolled by the individual species accommodation coefficients (Eq. 2). The following discussion explores the influence of changing the rate of halogen processing by the condensedphase on gas-phase chemistry. This has been achieved by running the 16-bin $\mathrm{S} / \mathrm{V}$ initialised model with three different accommodation coefficient scenarios: Base, Toyota and Low (Table 7).

The differences in gas-phase mixing ratios for these three scenarios are compared in Fig. 9. Reducing these accommodation coefficients reduces the cycling of halogens through the condensed-phase. Reducing the accommodation coefficients for the HOX (where $\mathrm{X}=\mathrm{Cl}, \mathrm{Br}$ or I) compounds increases the gas-phase mixing ratios of $\mathrm{HOBr}$, and decreases that of $\mathrm{Br}, \mathrm{BrO}$ and $\mathrm{HBr}$. The mixing ratios of $\mathrm{Cl}, \mathrm{ClO}$ and $\mathrm{HCl}$ and $\mathrm{OClO}$ are also reduced, as well as that of $\mathrm{HOCl}$. While the increase in $\mathrm{HOBr}$ is as expected, the reduction in $\mathrm{HOCl}$ seems counter-intuitive. Reducing the accommodation coefficients to the "Low" testcase further reductions in gasphase chlorine compounds are observed, except for $\mathrm{ClONO}_{2}$, which increases. $\mathrm{BrONO}_{2}$ mixing ratios also increase, and all iodine compounds (except for $\mathrm{OIO}$ and $\mathrm{IONO}_{2}$ ) decrease. The increases in $\mathrm{XONO}_{2}$ mixing ratios result straightforwardly from the reduced accommodation coefficients slow- 

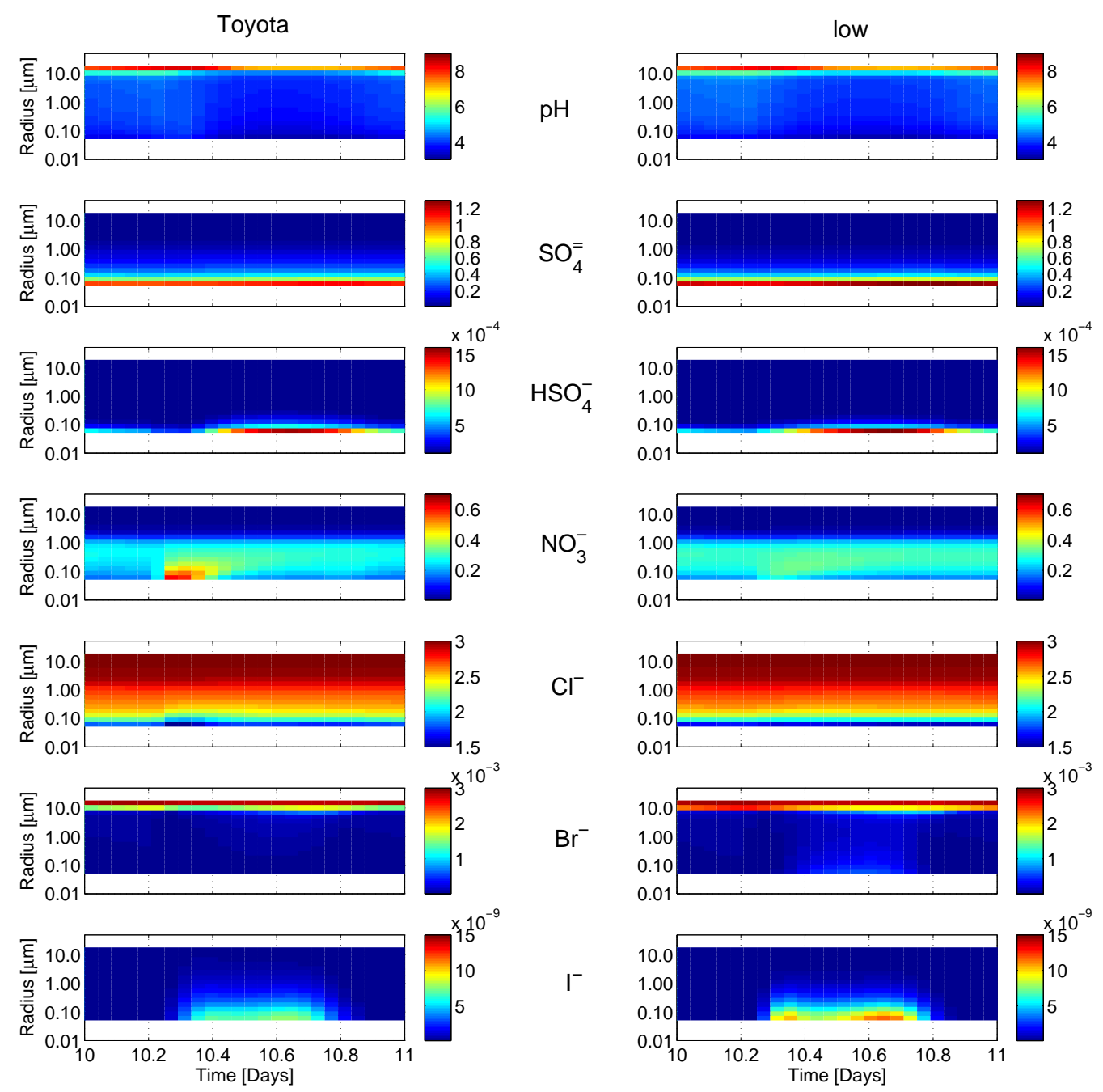

Fig. 11. Comparison of $\mathrm{pH}$ and nitrate, sulphate and halogen molalities $\left(\mathrm{mol} \mathrm{kg}_{\mathrm{H}_{2} \mathrm{O}}^{-1}\right)$ of the 16-bin $\mathrm{S} / \mathrm{V}$ initialised seasalt mode using the Toyota, and Low accommodation coefficient settings. The $\mathrm{pH}$ and molality data for the Base setting are shown in Fig. 7 (using the same colour scales). The seasalt aerosol turnover rate is calculated on-line.

ing the uptake of these species - which also reduces the uptake of nitrogen by the condensed-phase via these heterogeneous reactions. This increases $\mathrm{NO}_{\mathrm{x}}$ mixing ratios, although the $\mathrm{NO}_{\mathrm{x}}$ daytime maxima in all cases are within measured mixing ratio ranges $\left(<5 \mathrm{pmol} \mathrm{mol}^{-1}\right)$ of the remote MBL (cf. Torres and Thompson, 1993). At the same time reduces the halogen mixing ratios significantly below observed levels.

These changes lead to a reduction of the HOX and XO (and cross reactions) ozone destruction cycles, but with small increases in the $\mathrm{XONO}_{2}$ destruction cycles (Fig. 10). The $\mathrm{HOBr}$ and $\mathrm{HOI}$ cycles remain dominant, reaching maximum destruction rates of $\approx 0.2$ and $\approx 0.1 \% \mathrm{hr}^{-1}$, while the chlorine cycles all drop to a few hundredths of a percent ozone destruction, in-line with the reduction of $\mathrm{Cl}$ mixing ratios to about $0.001 \mathrm{pmol} \mathrm{mol}^{-1}\left(\approx 2.5 \times 10^{4}\right.$ molecule $\left.\mathrm{cm}^{-3}\right)$. This reduces the halogen contribution to ozone destruction to $\approx 0.3 \% \mathrm{hr}^{-1}$.
The changes observed in the gas-phase are mirrored in the condensed phase (Fig. 11). The seasalt particles take up less sulphuric and nitric acids, reducing their acidity and so reducing the activation and release of reactive chlorine and bromine across the whole size-range (though most noticeable for chlorine in the smallest particles). Conversely the daytime maxima of iodine in the smallest particles increases, also due to the reduced acidity of the aerosol.

\section{Conclusions}

In the model sensitivity studies above, it has been demonstrated that:

- It is important to realistically represent the physical properties on which the modelled physical processes depend; e.g. for condensational growth it is important 
Table 5. Comparison of the initial total moments (number, surface area and volume) of the seasalt mode for the three different initialisation methods (N/S, N/V and S/V). The surface areas and volumes are for the "dry" aerosol (i.e. without water). See text for details of initialising the seasalt mode.

\begin{tabular}{ccccc}
\hline & $\begin{array}{c}\text { Number of } \\
\text { Sections }\end{array}$ & $\begin{array}{c}\text { Number } \\
\left(\mathrm{cm}_{\text {air }}^{-3}\right)\end{array}$ & $\begin{array}{c}\text { Dry Surface Area } \\
\left(\mu \mathrm{m}^{2} \mathrm{~cm}_{\text {air }}^{-3}\right)\end{array}$ & $\begin{array}{c}\text { Dry Volume } \\
\left(\mu \mathrm{m}^{3} \mathrm{~cm}_{\text {air }}^{-3}\right)\end{array}$ \\
\hline \multirow{3}{*}{$\mathrm{N} / \mathrm{S}$} & 1 & 8.797 & 12.68 & 1.432 \\
& 1 & 8.797 & 12.68 & 5.600 \\
& 16 & 8.797 & 12.68 & 6.736 \\
$\mathrm{~N} / \mathrm{V}$ & 4 & 8.797 & 36.00 & 6.847 \\
& 16 & 8.797 & 14.76 & 6.847 \\
& 1 & 0.797 & 12.82 & 6.847 \\
$\mathrm{~S} / \mathrm{V}$ & 4 & 5.735 & 12.68 & 6.847 \\
& 16 & 8.514 & 12.68 & 6.847 \\
& & & 12.68 & 6.847 \\
\hline
\end{tabular}

to get the total aerosol surface area and volume correct (Sect. 3.1), while for aerosol turnover an accurate size distribution is needed (Sect. 3.2).

- Where the condensed-phase acts as a chemical source, replicating the size-resolution of chemistry is less important; e.g. greater differences in gas-phase ozone and halogen chemistry between model runs are caused by coarse representations of the physical characteristics of the condensed-phase than by coarsely-resolved condensed-phase chemistry (Sect. 3.2).

- Where the condensed-phase acts as an acid sink it is important to accurately represent the size-resolution of chemistry; e.g. differences still exist in gas-phase $\mathrm{HNO}_{3}$ mixing ratios between the 1-bin and 16-bin models even when physical processes are properly represented (Sect. 3.1).

Thus, when considering only gas-aerosol mass-transfer processes, it is only necessary to use one size-bin per aerosol mode to investigate ozone-destruction processes, provided the box-model is initialised with the correct aerosol volume and surface area. Toyota et al. (2001) observed differences between their "bulk model" and "type 1 size-segregated model" because the aerosol surface areas were not preserved in their study not because of any size-dependent chemical differences. Some physical processes, such as size-dependent turnover rates, do increase the chemical differences across the particle size-range which influence gas-phase chemistry, as demonstrated above and by the differences between the "type 1 size-segregated model" and "type 2 size-segregated model" in Toyota et al. (2001). These are, however, much less than those differences resulting from not preserving the important physical aerosol properties.
Table 6. Volumetrically-averaged seasalt aerosol turnover rates.

\begin{tabular}{ccc}
\hline $\begin{array}{c}\text { Size-resolution } \\
\text { (no. of bins) }\end{array}$ & $\begin{array}{c}\text { Aerosol lifetime } \\
\text { (days) }\end{array}$ & $\begin{array}{c}\text { Turnover rate } \\
\left(\mathrm{s}^{-1}\right)\end{array}$ \\
\hline 1 & 2.66 & $0.44 \times 10^{-5}$ \\
2 & 1.31 & $0.88 \times 10^{-5}$ \\
4 & 0.77 & $1.50 \times 10^{-5}$ \\
8 & 0.61 & $1.90 \times 10^{-5}$ \\
16 & 0.57 & $2.03 \times 10^{-5}$
\end{tabular}

Table 7. Accommodation coefficients of key halogen species used in the three different scenarios.

\begin{tabular}{|c|c|c|c|}
\hline \multirow{2}{*}{ Species } & \multicolumn{3}{|c|}{ Accommodation Coefficients } \\
\hline & Base & Toyota & Low \\
\hline $\mathrm{HOCl}$ & 0.5 & 0.01 & 0.01 \\
\hline $\mathrm{ClONO}_{2}$ & 0.1 & 0.1 & 0.01 \\
\hline $\mathrm{HOBr}$ & 0.5 & 0.01 & 0.01 \\
\hline $\mathrm{BrONO}_{2}$ & 0.8 & 0.8 & 0.01 \\
\hline HOI & 0.5 & 0.01 & 0.01 \\
\hline $\mathrm{IONO}_{2}$ & 0.1 & 0.1 & 0.01 \\
\hline $\mathrm{OIO}$ & 1.0 & 1.0 & 0.01 \\
\hline
\end{tabular}

a estimated; ${ }^{\mathrm{b}}$ Koch and Rossi (1998); ${ }^{\mathrm{c}}$ Abbatt and Waschewsky (1998); ${ }^{d}$ Hanson et al. (1996).

In contrast, to reproduce the temporal variations gas-phase mixing ratios of acid species such as $\mathrm{HNO}_{3}$ and $\mathrm{H}_{2} \mathrm{SO}_{4}$, sizeresolved condensed-phase chemistry is required.

Where multiple physical processes are being modelled, and so more than two aerosol microphysical properties are important, then a reduction in complexity cannot be made, and a higher aerosol size-resolution is needed. Any increase of resolution is useful, but eight or more size-bins is ideal.

To investigate halogen driven ozone-loss within a box model it is possible to use lumped chemistry bins on top of a size-resolved microphysical chemistry (e.g. von Glasow et al., 2002; Pszenny et al., 2004) without sacrificing much accuracy. However this may not hold true in non zerodimensional models, where turbulence and gravitational mixing may exaggerate the compositional gradients across the particle size-range which can be observed even when incorporating a simple size-dependent aerosol turnover function. Further investigation in this area is needed.

Acknowledgements. This work was carried out within the EUfunded Marine Aerosol Production (MAP, GOCE 018332) and UK NERC-funded Reactive Halogens in the Marine Boundary Layer (RHaMBLe, NE/D006570/1) projects. Our thanks to Roland von Glasow and anonymous referee for their helpful comments, which have helped improve this manuscript.

Edited by: R. Sander 


\section{References}

Abbatt, J. P. D. and Waschewsky, G. C. G.: Heterogeneous interactions of $\mathrm{HOBr}, \mathrm{HNO}_{3}, \mathrm{O}_{3}, \mathrm{NO}_{2}$ with deliquescent $\mathrm{NaCl}$ aerosols at room temperature, J. Phys. Chem. A, 102, 3719-3725, 1998.

Bott, A., Trautmann, T., and Zdunkowski, W.: A numerical model of the cloud-topped planetary boundary-layer: Radiation, turbulence and spectral microphysics in marine stratus, Q. J. R. Meteorol. Soc., 122, 635-667, 1996.

Carpenter, L., Sturges, W., Penkett, S., Liss, P., Alicke, B., Heibestreit, K., and Platt, U.: Short-lived alkyl iodides and bromides at Mace Head, Ireland: links to biogenic sources and halogen oxide production, J. Geophys. Res., 104, 1679-1689, 1999.

Carver, G. D., Brown, P. D., and Wild, O.: The ASAD atmospheric chemistry integration package and chemical reaction database, Comp. Phys. Comm., 105, 197-215, 1997.

Damian, V., Sandu, A., Damian, M., Potra, F., and Carmichael, G. R.: The Kinetic PreProcessor KPP - A Software Environment for Solving Chemical Kinetics, Comput. Chem. Eng., 26, 1567-1579, 2002.

Graedel, T. E. and Keene, W. C.: Tropospheric budget of reactive chlorine, Global Biogeochem. Cy., 9, 47-77, 1995.

Hanson, D. R., Ravishankara, A. R., and Lovejoy, E. R.: Reaction of $\mathrm{BrONO}_{2}$ with $\mathrm{H}_{2} \mathrm{O}$ on submicron sulfuric acid aerosol and the implications for the lower stratosphere, J. Geophys. Res., 101D, 9063-9069, 1996.

Jacobson, M. Z.: Development and Application of a new Air Pollution Modeling System - II. Aerosol Module Structure and Design, Atmos. Environ., 31, 131-144, 1997.

Keene, W. C., Khalil, M. A. K., Erickson, D. J., McCulloch, A., Graedel, T. E., Lobert, J. M., Aucott, M. L., Gong, S. L., Harper, D. B., Kleiman, G., Midgley, P., Moore, R. M., Seuzaret, C., Turges, W. T., Benkovitz, C. M., Koropalov, V., Barrie, L. A., and Li, Y. F.: Composite global emissions of reactive chlorine from anthropogenic and natural sources: Reactive Chlorine Emissions Inventory, J. Geophys. Res., 104, 8429-8440, 1999.

Keene, W. C., Pszenny, A. A. P., Maben, J. R., and Sander, R.: Variation of marine aerosol acidity with particle size, Geophys. Res. Lett., 29, 1101, doi:10.1029/2001GL013881, 2002.

Keene, W. C., Pszenny, A. A. P., Maben, J. R., Stevenson, E., and Wall, A.: Closure evaluation of size-resolved aerosol $\mathrm{pH}$ in the New England coastal atmosphere during summer, J. Geophys. Res., 109, doi:10.1029/2004JD004801, D23307, 2004.

Kerkweg, A., Sander, R., Tost, H., Jckel, P., and Lelieveld, J.: Technical Note: Simulation of detailed aerosol chemistry on the global scale using MECCA-AERO, Atmos. Chem. Phys., 7, 2973-2985, 2007,

http://www.atmos-chem-phys.net/7/2973/2007/.

Koch, T. G. and Rossi, M. J.: Direct measurement of surface residence times: Nitryl chloride and chlorine nitrate on alkali halides at room temperature, J. Phys. Chem. A, 102, 9193-9201, 1998.

McFiggans, G., Cox, R. A., Mössinger, J. C., Allan, B. J., and Plane, J. M. C.: Active chlorine release from marine aerosols: Roles for reactive iodine and nitrogen species, J. Geophys. Res., 107, doi: 10.1029/2001JD000383, 2002.

Pechtl, S., Lovejoy, E. R., Burkholder, J. B., and von Glasow, R.: Modeling the possible role of iodine oxides in atmospheric new particle formations, Atmos. Chem. Phys., 6, 505-523, 2006, http://www.atmos-chem-phys.net/6/505/2006/.
Porter, J. N. and Clarke, A. D.: Aerosol size distribution models based on in situ measurements, J. Geophys. Res., 102, 60356045, 1997.

Pszenny, A. A. P., Moldanov, J., Keene, W. C., Sander, R., Maben, J. R., Martinez, M., Crutzen, P. J., Perner, D., and Prinn, R. G.: Halogen cycling and aerosol $\mathrm{pH}$ in the Hawaiian marine boundary layer, Atmos. Chem. Phys., 4, 147-168, 2004, http://www.atmos-chem-phys.net/4/147/2004/.

Quinn, P. K., Bates, T. S., Johnson, J. E., Covert, D. S., and Charlson, R. J.: Interactions between the sulfur and reduced nitrogen cycles over the central Pacific Ocean, J. Geophys. Res., 95, 16405-16416, 1990.

Read, K. A., Mahajan, A. S., Carpenter, L. J., Evans, M. J., Faria, B. V. E., Heard, D. E., Hopkins, J. R., Lee, J. D., Moller, S. J., Lewis, A. C., Mendes, L., McQuaid, J. B., Oetjen, H., SaizLopez, A., Pilling, M. J., and Plane, J. M. C.: Extensive halogenmediated ozone destruction over the tropical Atlantic Ocean, Nature, 453, 1232-1235, doi:10.1038/nature07035, 2008.

Reilly, P. J. and Wood, R. H.: Predictions of Properties of Mixed Electrolytes from Measurements on Common Ion Mixtures, J. Phys. Chem., 73, 4292-4297, 1969.

Sander, R.: Modeling atmospheric chemistry: interactions between gas-phase species and liquid cloud/aerosol particles, Surv. Geophys., 20, 1-31, 1999.

Sander, R. and Crutzen, P. J.: Model study indicating halogen activation and ozone destruction in polluted air masses transported to the sea, J. Geophys. Res., 101, 9121-9138, 1996.

Sander, R., Keene, W. C., Pszenny, A. A. P., Arimoto, R., Ayers, G. P., Baboukas, E., Cainey, J. M., Crutzen, P. J., Duce, R. A., Hönninger, G., Huebert, B. J., Maenhaut, W., Mihalopoulos, N., Turekian, V. C., and Van Dingenen, R.: Inorganic bromine in the marine boundary layer: a critical review, Atmos. Chem. Phys., 3, 1301-1336, 2003, http://www.atmos-chem-phys.net/3/1301/2003/.

Sandu, A., Verwer, J. G., van Loon, M., Carmichael, G. R., Potra, F. A., Dabdub, D., and Seinfeld, J. H.: benchmarking stiff ODE solvers for atmospheric chemistry problems - I. implicit vs. explicit, Atmos. Environ., 31, 3151-3166, 1997.

Schwartz, S. E.: Mass-transport considerations pertinent to aqueous phase reactions of gases in liquid-water clouds, in: Chemistry of Multiphase Atmospheric Systems, edited by: Jaeschke, W., Springer-Verlag, New York, USA, 415-471, 1986.

Slinn, S. A. and Slinn, W. G. N.: Predictions for particle deposition on natural waters, Atmos. Environ., 14, 1013-1016, 1980.

Sportisse, B.: An Analysis of Operator Splitting Techinques in the Stiff Case, J. Comput. Phys., 161, 140-168, 2000.

Tang, I. N.: Thermodynamic and optical properties of mixedsalt aerosols of atmospheric importance, J. Geophys. Res., 102, 1883-1893, 1997.

Topping, D., McFiggans, G., and Lowe, D.: A hybrid mixing rule / explicit thermodynamic approach for calculating gas/liquid equilibria in atmospheric aerosol particles - 1 Inorganic compounds, J. Geophys. Res., D04304, doi:10.1029/2008JD010099, 2009.

Topping, D. O., McFiggans, G. B., and Coe, H.: A curved multicomponent aerosol hygroscopicity model framework: Part 1 - Inorganic compounds, Atmos. Chem. Phys., 5, 1205-1222, 2005, http://www.atmos-chem-phys.net/5/1205/2005/.

Torres, A. L. and Thompson, A. M.: Nitric Oxide in the Equatorial Pacific Boundary Layer: SAGA 3 Measurements, J. Geophys. 
Res., 98, 16949-16954, 1993.

Toyota, K., Takahashi, M., and Akimoto, H.: Modeling multiphase halogen chemistry in the marine boundary layer with size-segregated aerosol module: Implications for quasi-sizedependent approach, Geophys. Res. Lett., 28, 2899-2902, 2001.

Vogt, R., Sander, R., von Glasow, R., and Crutzen, P. J.: Iodine Chemistry and its Role in Halogen Activation and Ozone Loss in the Marine Boundary Layer: A Model Study, J. Atmos. Chem., 32, 375-395, 1999.

von Glasow, R., Sander, R., Bott, A., and Crutzen, P. J.: Modeling halogen chemistry in the marine boundary layer 1 . Cloud-free MBL, J. Geophys. Res., 107, 4341, doi:10.1029/2001JD000942, 2002.
Zafiriou, O. C., McFarland, M., and Bromund, R. H.: Nitric oxide in seawater, Science, 207, 637-639, 1980.

Zaveri, R. A., Easter, R. C., and Wexler, A. S.: A new method for multicomponent activity coefficients of electrolytes in aqueous atmospheric aerosols, J. Geophys. Res., 110, D02201, doi:10. 1029/2004JD004681, 2005. 